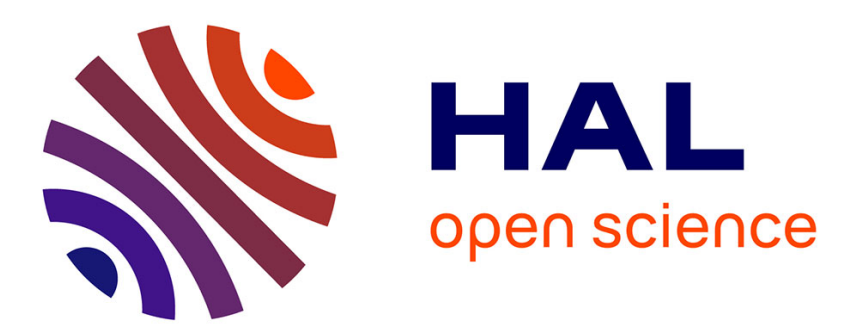

\title{
Electrolyte CPA equation of state for very high temperature and pressure reservoir and basins applications.
}

Xavier Courtial, Nicolas Ferrando, Jean-Charles de Hemptinne, Pascal Mougin

\section{- To cite this version:}

Xavier Courtial, Nicolas Ferrando, Jean-Charles de Hemptinne, Pascal Mougin. Electrolyte CPA equation of state for very high temperature and pressure reservoir and basins applications.. Geochimica et Cosmochimica Acta, 2014, 142 (October 1st), pp.1-14. 10.1016/j.gca.2014.07.028 . hal-01076995

\section{HAL Id: hal-01076995 \\ https://hal-ifp.archives-ouvertes.fr/hal-01076995}

Submitted on 23 Oct 2014

HAL is a multi-disciplinary open access archive for the deposit and dissemination of scientific research documents, whether they are published or not. The documents may come from teaching and research institutions in France or abroad, or from public or private research centers.
L'archive ouverte pluridisciplinaire HAL, est destinée au dépôt et à la diffusion de documents scientifiques de niveau recherche, publiés ou non, émanant des établissements d'enseignement et de recherche français ou étrangers, des laboratoires publics ou privés. 


\title{
Electrolyte CPA equation of state for very high temperature and pressure reservoir and basins applications
}

\author{
Xavier Courtial a, Nicolas Ferrando a, Jean-Charles de Hemptinne a, Pascal Mougin a
}

a IFP Energies nouvelles, 1 et 4 avenue de Bois-Préau, 92852 Rueil-Malmaison, France

\begin{abstract}
In this work, an electrolyte version of the Cubic Plus Association (eCPA) equation of state has been adapted to systems containing $\mathrm{CH}_{4}, \mathrm{CO}_{2}, \mathrm{H}_{2} \mathrm{O}$ and $\mathrm{NaCl}$ (up to 5 molal) at temperatures and pressures up to $773 \mathrm{~K}$ and $200 \mathrm{MPa}$. Its purpose is to represent the phase behavior (including saltingout effect and critical point) and the phase densities in a range of temperature and pressure encountered in deep reservoir and basins. The goal of the parameterization proposed is not to reach a very high accuracy for phase equilibrium and volumetric properties, but rather to develop a semipredictive approach to model the different phase and volumetric behaviors of this system while allowing an easy extension to other compounds.
\end{abstract}

Without salt, predictions for pure component vapor pressures and liquid molar volumes present an average absolute deviation (AAD) lower than $3 \%$ compared to experimental reference values. The pure component molar volumes out of saturation show an AAD lower than $4 \%$. The highest deviations in densities are observed as expected in the vicinity of the critical coordinates of pure water and this effect increases when gases or salts are added to the system. For each binary system, $\mathrm{CH}_{4}+$ $\mathrm{CO}_{2}, \mathrm{CH}_{4}+\mathrm{H}_{2} \mathrm{O}$ and $\mathrm{CO}_{2}+\mathrm{H}_{2} \mathrm{O}$, binary interaction parameters have been fitted to correctly predict the shape of the fluid phase envelopes (including all critical points) in the entire temperature and pressure range considered $(219 \mathrm{~K}$ to $633 \mathrm{~K}$ and up to $250 \mathrm{MPa}$ ). The methane concentration in both phases of the $\mathrm{CH}_{4}+\mathrm{CO}_{2}$ binary system is represented with an AAD lower than $9 \%$. The methane solubility in water is represented within $16 \%$ and $8 \%$ for the methane content of the vapor. The $\mathrm{CO}_{2}$ solubility in water is within $26 \%$, while the $\mathrm{CO}_{2}$ in the vapor phase shows an average deviation of $12 \%$. All molar volumes are represented with an AAD lower than $3 \%$. The few VLE experimental data which were found for the $\mathrm{CH}_{4}+\mathrm{CO}_{2}+\mathrm{H}_{2} \mathrm{O}$ ternary system are fairly well predicted with the model without extra parameter and comfort the ability of the eCPA equation of state to be extended to multi-component systems. In the presence of salts, gas + ion binary interaction parameters have been fitted, and all phase equilibrium are qualitatively correctly described, and more specifically the salting out effect. The solubility of methane or $\mathrm{CO}_{2}$ in brines, up to 5 molal, is represented with an AAD of $33 \%$ in a large temperature and pressure range (up to $673 \mathrm{~K}$ and $150 \mathrm{MPa}$ ). It should be noticed that for high temperatures, experimental data are relatively scarce and not always consistent. No data exist for water content of the vapor phase in these conditions.

The new eCPA model can be easily extended to other components (including ions) to better represent real fluid behavior in very deep reservoir conditions.

Keywords: Vapor liquid equilibrium, volumetric behavior, electrolyte CPA equation of state (eCPA), $\mathrm{NaCl}$ electrolyte, water, $\mathrm{CO}_{2}, \mathrm{CH}_{4}$, critical point. 


\section{Introduction}

Nowadays, oil and gas operators are exploring ever deeper reservoirs and basins where temperature and pressure can be very important. Typical fluids encountered are composed of salt water with hydrocarbons and light gases such as methane or carbon dioxide. To understand and model fluid behavior in extreme conditions of temperature and pressure, it is necessary to rely on a thermodynamic model able to predict densities and phase equilibrium of real fluids, including mutual solubilities, critical points and salinity effects.

A common approach to calculate phase equilibrium in geophysical applications consists in associating an electrolyte activity model (e.g. Pitzer model (Pitzer, 1973)) to calculate the activity of the various species in the aqueous phase, and an equation of state to calculate the fugacity of the compounds in the vapor phase (e.g. Duan et al., 1992b; Duan et al., 2006; Duan and Mao, 2006; Duan and Sun, 2003; He and Morse, 1993). Although quite accurate, such an approach is restricted to the subcritical domain: at the critical point, properties of the liquid and the vapor phases converge, which is not ensured if a different model is used for each phase. Moreover, using a model based on activity coefficients for the liquid phase does not allow to calculate its density. A homogeneous thermodynamic approach is thus needed to predict densities and phase equilibrium in both subcritical and supercritical conditions: this means that the same equation of state should be used to model both liquid and vapor phases. The availability of equations of state able to treat electrolytic systems in very high temperature and pressure ranges is very limited in the literature. Soreide and Whitson (Soreide and Whitson, 1992) have proposed a model based on the Peng-Robinson equation of state. The attractive term of water in the liquid phase is corrected to take into account the salinity of the solution, while the attractive term of water in the vapor phase remains unchanged. Thus, this model behaves similarly as with a heterogeneous approach (different binary parameters for each phase), making critical point calculations impossible. Sorensen et al.(Sorensen et al., 2002) have proposed to model gas solubility in brines using the Soave-Redlich-Kwong equation of state coupled with the HuronVidal mixing rules. However, this approach has been tested only in subcritical domain, and is not suitable to calculate accurately liquid phase densities. More recently, Ji et al. (Ji et al., 2005) have modeled the $\mathrm{CO}_{2}+\mathrm{H}_{2} \mathrm{O}+\mathrm{NaCl}$ system using an electrolyte version of the SAFT equation of state. This model appears accurate to predict both phase densities and phase equilibrium, but it is restricted in temperature $(473 \mathrm{~K})$ and pressure $(60 \mathrm{MPa})$ and does not cover the supercritical domain. For many years, Duan's group has developed specific equations of states which are today widely used for geochemical applications. These models are often parameterized to reproduce either phase equilibrium (e.g. Duan et al., 1992a; Duan et al., 2003) or volumetric properties (e.g. Duan et al., 1996; Hu et al., 2007; Mao et al., 2010) with very good accuracy. Many empirical interaction parameters (binary, ternary and quaternary parameters) have to be adjusted, requiring thus a large number of experimental data. Although very accurate, such models are not fairly predictive.

In this work, we propose another model to represent simultaneously phase equilibrium and volumetric properties of geological fluids (including electrolytes) for high temperature and high pressure applications: the electrolyte Cubic Plus Association equation of state (eCPA). Initially developed for water + salts systems (Inchekel et al., 2008), this equation of state has been extended to electrolytic systems involving methane but in a restricted temperature range (de Hemptinne et al., 2006). In this work we propose an extension of this model to the system $\mathrm{CH}_{4}+\mathrm{CO}_{2}+\mathrm{H}_{2} \mathrm{O}+\mathrm{NaCl}$ for a wide range of temperatures (up to $773 \mathrm{~K}$ ) and pressures (up to $200 \mathrm{MPa}$ ). Our goal is not to reach a very high accuracy for phase equilibrium and volumetric properties, but rather to develop a semi- 
predictive approach to model this system while allowing an easy extension to other compounds. This is achieved using an equation that is now widely accepted, has semi-theoretical foundations (Kontogeorgis, 2006), and has a small number of empirical parameters. Doing so, phase densities, gas solubility, critical points and salting out effect are correctly estimated.

This paper is organized as follows: the eCPA model is detailed in section 2 with a description of the various contributions to the total Helmholtz free energy. In section 3 we present the parameters that are used to model pure component properties (excluding salt). Section 4 is devoted to the $\mathrm{H}_{2} \mathrm{O}+$ $\mathrm{NaCl}$ system: the parameters used to represent properties (up to 7 molal $\mathrm{NaCl}$ ) are presented together with the deviations between experimental data and representation from the model. The selected physical properties are vapor pressure, molar volumes at and out of saturation, $\mathrm{NaCl}$ mean activity coefficient and osmotic coefficient. Section 5 treats the modeling of the binary salt-free systems $\mathrm{CH}_{4}+\mathrm{CO}_{2}, \mathrm{CH}_{4}+\mathrm{H}_{2} \mathrm{O}$ and $\mathrm{CO}_{2}+\mathrm{H}_{2} \mathrm{O}$, with a focus on the description of the critical point. Finally, the modeling of the full system with $\mathrm{CH}_{4}+\mathrm{CO}_{2}+\mathrm{H}_{2} \mathrm{O}+\mathrm{NaCl}$ is presented in section 6 .

\section{Model}

Modeling phase equilibrium of the $\mathrm{CH}_{4}+\mathrm{CO}_{2}+\mathrm{H}_{2} \mathrm{O}+\mathrm{NaCl}$ system is quite complex due to the combination of different types of components such as water, gas as well as ionic species. $\mathrm{The}^{\mathrm{CH}_{4}}$ $+\mathrm{CO}_{2}$ binary system does not exhibit strong non ideality and is satisfactorily represented using a conventional cubic equation of state such as Soave-Redlich Kwong (SRK) (Soave, 1972). Yet, the hydrogen bonds result in a strong organization of water molecules. This supplementary degree of complexity can be obtained with the Cubic Plus Association model (CPA) proposed by Kontogeorgis et al.(Kontogeorgis et al., 1996). Finally, $\mathrm{NaCl}$ dissociates when dissolved in water to form ions and electrostatic interactions are added to this complex system. The electrolyte Cubic Plus Association, as proposed by Inchekel et al. (eCPA) (Inchekel et al., 2008) uses two electrolyte terms and its residual Helmholtz free energy can be written as a combination of different contributions:

$$
A^{r e s}=A^{S R K}+A^{a s s o c}+\left(A^{M S A}+A^{\text {Born }}\right)
$$

$A^{S R K}$ is relative to Van de Waals interactions (attraction, repulsion) and is based on the work of Soave (Soave, 1972). It is expressed as:

$$
\frac{A^{S R K}}{R T}=\frac{\sum_{i} \sum_{j} n_{i} n_{j} a_{i j}}{R T \sum_{i} n_{i} b_{i}} \ln \frac{V}{V+\sum_{i} n_{i} b_{i}}+\sum_{i} n_{i} \ln \frac{V}{V-\sum_{i} n_{i} b_{i}}
$$

Where $n$ stands for the number of mole, $R$ is the ideal gas constant, $T$ is the absolute temperature, $V$ the volume, $a$ the attractive parameter and $b$ the covolume.

The attractive parameter $\left(a_{i j}\right)$ between species $i$ and $j$ is obtained from a classical mixing rule:

$$
a_{i j}=\sqrt{a_{i} a_{j}}\left(1-k_{i j}\right)
$$

Where $a_{i}$ stands for the attractive parameter for the pure compound $i$, and $k_{i j}$ (by default set to zero) allows to empirically tune interactions between species.

The Soave alpha function (Soave, 1972) is used to represent the temperature dependency of the attractive parameter for non-ionic species: 


$$
a_{i}(T)=a_{c, i}\left[1+m_{i} \cdot\left(1-\sqrt{T / T_{c, i}}\right)\right]^{2}
$$

$T$ is in $\mathrm{K}$ and the specific parameters to each species used in this term $\left(a_{c, i}, m_{i}\right.$ and $\left.T_{c, i}\right)$ are presented in the Table 1, together with $b_{i}$ of the equation (2).

For ions a similar formalism is used, but as their critical temperature is not clearly defined, it is substituted by the reference temperature of $298.15 \mathrm{~K}$, because most data are available at that temperature. The attractive parameter for ionic species is therefore written as:

$$
a_{i}(T)=a_{0, i}\left[1+m_{i} \cdot(1-\sqrt{T / 298.15})\right]^{2}
$$

In order to limit the number of parameters of the model, the repulsive term for the ions is obtained from the ionic diameter $\left(\sigma_{b}^{h s}\right)$, which will be used for electrolyte terms of the equation of state, as:

$$
b_{i}=\frac{N_{a v} \pi\left(\sigma_{b, i}^{h s}\right)^{3}}{6}
$$

Where $N_{a v}$ is Avogadro's constant.

The term $A^{\text {asso }}$ in equation (1) accounts for association phenomena between species and especially for hydrogen bonds formation. It originates from Wertheim's theory (Wertheim, 1984). It can be expressed as:

$$
\frac{A^{a s s o c}}{R T}=\sum_{i} n_{i} \sum_{A_{i}}\left(\ln \left(X^{A_{i}}\right)-\frac{1}{2} X^{A_{i}}+\frac{1}{2}\right)
$$

$X^{A_{i}}$ describes the non-bonded fraction of associating sites of type $A$ of the compound $i$ and is obtained by solving :

$$
X^{A_{i}}=\frac{1}{\left[1+\rho \sum_{j} x_{j} \sum_{B_{j}}\left(X^{B_{j}} \Delta^{A_{i} B_{j}}\right)\right]}
$$

Where $\rho$ is the molar density and $x_{j}$ the molar fraction of the compound $j$. The association strength $\left(\triangle^{A_{i} B_{j}}\right)$ between two sites is calculated as follows:

$$
\Delta^{A_{i} B_{j}}=g(\rho)\left[\exp \left(\varepsilon^{A_{i} B_{j}} / R T\right)-1\right] b_{i j}^{3} \beta^{A_{i} B_{j}}
$$

In this equation, $g(\rho)$ is the simplified radial distribution function and is obtained from :

$$
g(\rho)=\frac{1}{1-1.9 \frac{n b}{4 V}}
$$

Where :

$$
b=\sum_{i} \sum_{j} x_{i} x_{j} b_{i j}
$$

With: 


$$
b_{i j}=\frac{b_{i}+b_{j}}{2}
$$

$\varepsilon^{A_{i} B_{j}}$ and $\beta^{A_{i} B_{j}}$ are interaction parameters between associating sites. They are determined from pure compound parameters using the so-called ' $\mathrm{CR} 1$ ' combining rule (Derawi, 2002):

$$
\begin{aligned}
& \varepsilon^{A_{i} B_{j}}=\frac{\varepsilon^{A_{i}}+\varepsilon^{B_{j}}}{2} \\
& \beta^{A_{i} B_{j}}=\sqrt{\beta^{A_{i}} \beta^{B_{j}}}
\end{aligned}
$$

An important parameter for the calculation of this energy is the number and the type of associating sites for each compound. In this work, a $4 \mathrm{C}$ association scheme is adopted for water, according to the nomenclature of Huang and Radosz (Huang and Radosz, 1990). It means that a molecule of water has two electronegative sites and two electropositive sites. The $\mathrm{CO}_{2}$ molecule is modeled with a single electronegative site. It means that a $\mathrm{CO}_{2}$ molecule cannot be associated with another $\mathrm{CO}_{2}$ molecule, but only with an electropositive site of water, thus mimicking the formation of carbonates.

Electrostatic interactions (ionic species) are considered with the $A^{M S A}$ term from the Mean Spherical Approximation (MSA) approach detailed by Blum (Blum, 1975; Blum, 1977) from the expression of Ball et al.(Ball et al., 1985):

$$
\frac{A^{M S A}}{R T}=-\frac{N_{A v} e^{2}}{4 \pi D_{0} D R T} \sum_{i} \frac{n_{i} Z_{i}^{2} \Gamma}{1+\Gamma \sigma_{b, i}^{M S A}}+\frac{V \Gamma^{3}}{3 \pi N_{A v}}
$$

The screening length $(\Gamma)$ is obtained by solving iteratively:

$$
4 \Gamma^{2}=\frac{N_{a v} e^{2}}{D_{0} D R T} \sum_{i} \frac{n_{i}}{V}\left(\frac{Z_{i}^{2}}{1+\Gamma \sigma_{b, i}^{M S A}}\right)
$$

$D$ is the solution relative dielectric constant, $D_{0}$ is the vacuum permittivity $\left(8.855 .10^{-12} \mathrm{~F} \cdot \mathrm{m}^{-1}\right) ; e$ is the elementary charge $\left(1.602 .10^{-19} \mathrm{C}\right) ; Z_{i}$ is the valence of ion $i$ and $\sigma_{b, i}^{M S A}$ is the diameter of ion $i$.

The relative dielectric constant of the solution $(D)$ is obtained from the value of pure water $\left(D_{s}\right)$ using the Schmidt correlation (Schmidt and Grigull, 1982), coupled to Simonin's model (Simonin, $1997)$ to account for salinity. The Schmidt correlation is the following:

$$
\begin{aligned}
& D_{s}=1+\left(\frac{7.62571}{T^{*}}\right) \rho^{*}+\left(\frac{244.003}{T^{*}}-140.569+27.7841 T^{*}\right) \rho^{* 2} \\
& +\left(\frac{-96.2805}{T^{*}}+41.7909 T^{*}-10.2099 T^{* 2}\right) \rho^{* 3}+\left(\frac{-45.2059}{T^{* 2}}+\frac{84.6395}{T^{*}}-35.8644\right) \rho^{* 4}
\end{aligned}
$$

Where $T^{*}=\frac{T}{298.15}(T$ in $\mathrm{K})$ and $\rho^{*}=\frac{v_{0}}{v}$ with $v_{0}$ : molar volume of pure water at atmospheric pressure and $278.15 \mathrm{~K}\left(v_{0}=18 \cdot 10^{-6} \mathrm{~m}^{3} / \mathrm{mol}\right)$ and $v$ : molar volume of the solution.

The Simonin model is expressed as:

$$
D=\frac{D_{s}}{1+\sum_{i}^{\text {ioms }} \alpha_{i} x_{i}}
$$


As suggested by Inchekel et al. (Inchekel et al., 2008), the tunable parameter $\alpha_{i}$, is set to 5.08 for the $\mathrm{H}_{2} \mathrm{O}+\mathrm{NaCl}$ system. This value represents fairly well the decrease of the dielectric constant of the system while salinity increases.

The difference of permittivity between the ideal gas reference state, assimilated to vacuum permittivity, and the permittivity of the ionic solution is taken into account in the residual Helmoltz energy calculation by the $A^{B o r m}$ term (Born, 1920) expressed as:

$\frac{A^{B o r n}}{R T}=-\frac{N_{a v} e^{2}}{4 \pi D_{0} R T}\left(1-\frac{1}{D}\right) \sum_{i} \frac{n_{i} Z_{i}^{2}}{\sigma_{b, i}^{B o r n}}$

$\sigma_{b, i}^{B o m}$ is the diameter of the ion $i$ and in order to reduce the number of parameters, we chose to use:

$$
\sigma_{b, i}^{h s}=\sigma_{b, i}^{M S A}=\sigma_{b, i}^{B o m}=\sigma_{b, i}
$$

In this work, $\mathrm{NaCl}$ is assumed to be excluded from the vapor phase if two fluid phases coexist. Similarly, we consider totally dissociated $\mathrm{Na}^{+}$and $\mathrm{Cl}^{-}$ions in the dense phase. So 1 mole of $\mathrm{NaCl}$ in the system accounts for 2 moles of ions. Both of these assumptions are not entirely correct, especially when the fluid approaches the critical point of water, but the resulting system description was sufficient for our purpose.

\section{Pure compounds properties}

Parameters for pure components excluding ions $\left(\mathrm{Na}^{+}\right.$and $\left.\mathrm{Cl}^{-}\right)$are the ones proposed by Kontogeorgis's group (Kontogeorgis et al., 2008; Tsivintzelis et al., 2010; Tsivintzelis et al., 2011) and can be found in Table 1. Only cross-associating volume of $\mathrm{CO}_{2}$ (which has no effect on pure component properties) has been adjusted in this work to obtain a better accuracy for phase equilibrium of $\mathrm{CO}_{2}+\mathrm{H}_{2} \mathrm{O}$ binary system specifically at high temperature.

Table 1. Pure component parameters used for eCPA equation of state. $T_{c}$ is the critical temperature, $a_{c}$ the attractive term at the critical point, $b$ the covolume, $m$ the parameter used in equation (4), $\varepsilon$ the association energy parameter, $\beta$ the association volume parameter. In the association scheme, $e d$ stands for electron donor, ea for electron acceptor.

\begin{tabular}{|c|c|c|c|c|c|c|c|c|}
\hline & $\mathrm{Tc}(\mathrm{K})$ & $\begin{array}{c}\mathrm{a}_{\mathrm{c}} \\
\left(\mathrm{Pa} \cdot \mathrm{m}^{6} \cdot \mathrm{mol}^{-1}\right)\end{array}$ & $\mathrm{b}\left(\mathrm{m}^{3} \cdot \mathrm{mol}^{-1}\right)$ & $\mathrm{m}(-)$ & $\begin{array}{c}\text { number of } \\
\text { associating site }\end{array}$ & $\begin{array}{c}\text { Association } \\
\text { scheme }\end{array}$ & $\varepsilon / \mathrm{R}(\mathrm{K})$ & $\beta\left(\mathrm{m}^{3} \cdot \mathrm{mol}^{-1}\right)$ \\
\hline $\begin{array}{c}\mathrm{H}_{2} \mathrm{O} \\
\text { et al., 2008) }\end{array}$ & 647.35 & 0.122735 & 0.0000145 & 0.67359 & 4 & $\begin{array}{c}\text { 2ed-2ea } \\
(4 \mathrm{C})\end{array}$ & 2003.12 & 0.06920 \\
\hline $\begin{array}{c}\mathrm{CO}_{2} \\
\text { (Tsivinizelis } \\
\text { et al., 2011) }\end{array}$ & 304.19 & 0.350790 & 0.0000272 & 0.76020 & 1 & $0 \mathrm{ed}-1 \mathrm{ea}$ & 1412.59 & $0.01313^{*}$ \\
\hline $\begin{array}{c}\mathrm{CH}_{4} \\
\text { (Tsivintzelis } \\
\text { et al., 2010) }\end{array}$ & 190.55 & 0.232040 & 0.0000291 & 0.44718 & 0 & - & - & - \\
\hline
\end{tabular}

*: the association volume of $\mathrm{CO}_{2}$ was adapted compared to the original (Tsivintzelis et al., 2011). 
Properties of pure components at saturation (vapor pressure and liquid molar volume) have been compared to the DIPPR correlations (Rowley et al., 2011), while densities out of saturation are confronted to representation from the REFPROP software (Lemmon, 2006).

Deviations are presented as Average Absolute Deviation (AAD), defined as:

$$
A A D(\%)=\frac{100}{N_{\text {data }}} * \sum_{N_{\text {data }}}\left|\frac{F_{c a l}-F_{\text {exp }}}{F_{\text {exp }}}\right|
$$

Where $N_{\text {data }}$ is the number of data, $F$ a physical property such as pressure, molar volume, phase composition, osmotic coefficient or mean activity coefficient, which is either calculated from the model $(c a l)$, or originating from experimental data (exp).

The Table 2 shows AAD for vapor pressures, saturated liquid molar volumes and molar volumes out of saturation for pure $\mathrm{H}_{2} \mathrm{O}, \mathrm{CO}_{2}$ and $\mathrm{CH}_{4}$.

Table 2. AAD (\%) for pure compound properties

\begin{tabular}{|c|c|c|c|}
\hline & Vapor pressure & $\begin{array}{c}\text { Saturated liquid molar } \\
\text { volumes }\end{array}$ & $\begin{array}{c}\text { Out of saturation molar } \\
\text { volumes }\end{array}$ \\
\hline $\mathrm{H}_{2} \mathrm{O}$ & 0,9 & 1,8 & 2,0 \\
\hline $\mathrm{CO}_{2}$ & 0,6 & 1,5 & 3,7 \\
\hline $\mathrm{CH}_{4}$ & 1,2 & 2,8 & 2,5 \\
\hline
\end{tabular}

For each compound, vapor pressures are very well represented from triple point to critical point with an $\mathrm{AAD}$ lower than $1.2 \%$ and the highest deviations are lower than $3 \%$. Liquid molar volumes at saturation are fairly well represented with an AAD lower than $3 \%$. The highest deviations are focused in the vicinity of critical points, with deviations as high as $15 \%$ for water. Representation of densities out of saturation with eCPA model agrees well with the representations from REFPROP software for each component from $373 \mathrm{~K}$ to $773 \mathrm{~K}$ and from 10 to $250 \mathrm{MPa}$. AAD are lower than $4 \%$ for the three components. Deviations for methane are homogeneous in the investigated conditions, even if it increases with pressure. A similar behavior is observed with carbon dioxide, with higher degradation of the representation at very high pressures. Water densities out of saturation are generally well represented for the entire range of temperature and pressure studied and the highest deviations are found from its critical point to $773 \mathrm{~K}$ and $50 \mathrm{MPa}$ with deviations about $10 \%$.

\section{4. $\mathrm{H}_{2} \mathrm{O}+\mathrm{NaCl}$ system}

As $\mathrm{NaCl}$ is the only salt studied in this work, it has been chosen to use the same values of attractive parameters (equation 5) for both ions $\mathrm{Na}^{+}$and $\mathrm{Cl}^{-}$to represent the physical properties of salt water. The pure ion parameters have been adjusted on salt water vapor pressures, saturated and out of saturation molar volumes, $\mathrm{NaCl}$ average activity coefficients and water osmotic coefficients, for molalities up to 7 . The optimized parameters are given in Table 3.

The segment diameter parameter accounts for electrolytic contributions as well as repulsion forces, and differs for $\mathrm{Na}^{+}$and $\mathrm{Cl}^{-}$. 
Table 3. Parameters for ions used for eCPA equation of state. $\sigma_{b}$ is the solvated diameter of the ion (equation (20)), and $a_{0}$ and $m_{1}$ the parameters of equation (5).

\begin{tabular}{|c|c|c|c|}
\cline { 2 - 4 } \multicolumn{1}{c|}{} & $\sigma_{\mathrm{b}}(\AA)$ & $\mathrm{a}_{0(\mathrm{~T} 0=298 \mathrm{~K})}\left(\mathrm{Pa} \cdot \mathrm{m}^{6} \cdot \mathrm{mol}^{-2}\right)$ & $\mathrm{m}_{\mathrm{I}}$ \\
\hline $\mathrm{Na}^{+}$ & 1.6 & 1.162 & -0.987 \\
\hline $\mathrm{Cl}^{-}$ & 4.3 & & \\
\hline
\end{tabular}

Table 4 shows the AAD obtained using this parameterization for various properties of the $\mathrm{H}_{2} \mathrm{O}$ $+\mathrm{NaCl}$ system, as well as the number of experimental data, the temperature range and the maximal salinity of the experimental data used for the regression.

Table 4. $\mathrm{AAD}(\%)$ for $\mathrm{H}_{2} \mathrm{O}+\mathrm{NaCl}$ properties. 


\begin{tabular}{|c|c|c|c|c|c|}
\hline & AAD \% & $n$ data & $\begin{array}{c}\text { Temperature } \\
\text { range }\end{array}$ & $\begin{array}{c}\text { Salinity max. } \\
\text { (molality) }\end{array}$ & Ref. \\
\hline $\begin{array}{l}\text { Saturated } \\
\text { vapor } \\
\text { pressure }\end{array}$ & 2.7 & 1094 & {$[298 ; 673 \mathrm{~K}]$} & 7.8 & 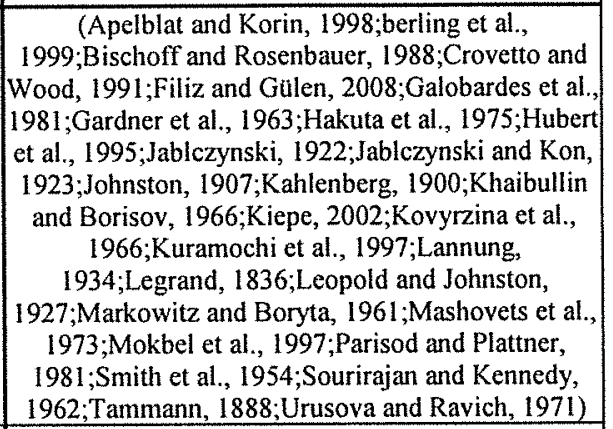 \\
\hline $\begin{array}{l}\text { Molar } \\
\text { volume at } \\
\text { saturation }\end{array}$ & 4.6 & 1238 & {$[273 ; 713 \mathrm{~K}]$} & 5.7 & $\begin{array}{c}\text { (Apelblat and Manzurola, 1999;Elis and Golding, } \\
\text { 1963;Fabuss et al., 1966;Khaibullin and Borisov, } \\
\text { 1966;Kiepe et al., 2003a;Korosi and Fabuss, } \\
\text { 1968;Patel and Kishore, 1995;Potter and Brown, } \\
\text { 1977;Rodnyanskii and Galinker, 1955;Rogers and } \\
\text { Pitzer, 1982;Shreiber and Tikhii, 1973) } \\
\end{array}$ \\
\hline \begin{tabular}{|c|} 
Molar \\
volume out \\
of saturation
\end{tabular} & 4.0 & 5947 & {$[273 ; 773 \mathrm{~K}]$} & 5.7 & \begin{tabular}{|c|} 
(Ellis, 1966;Gehrig et al., 1983;Gorbatchev et al., \\
1974;Grant-Taylor, 1981;Hilbert, 1979; Potter and \\
Brown, 1977; Rogers and Pitzer, 1982;Zarembo and \\
Fedorov, 1975)
\end{tabular} \\
\hline$\left|\begin{array}{c}\mathrm{NaCl} \text { mean } \\
\text { ionic } \\
\text { activity } \\
\text { coefficient }\end{array}\right|$ & 3.0 & 1021 & {$[298 ; 573 \mathrm{~K}]$} & 6.7 & 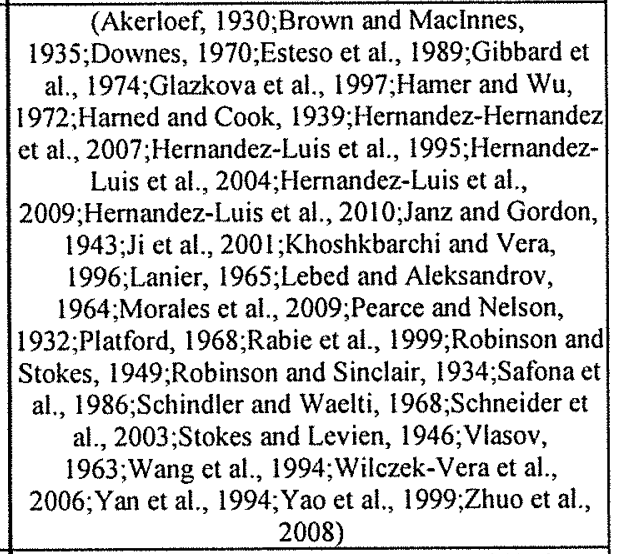 \\
\hline $\begin{array}{c}\mathrm{H}_{2} \mathrm{O} \\
\text { osmotic } \\
\text { coefficient }\end{array}$ & 2.5 & 752 & {$[298 ; 573 \mathrm{~K}]$} & 10.2 & 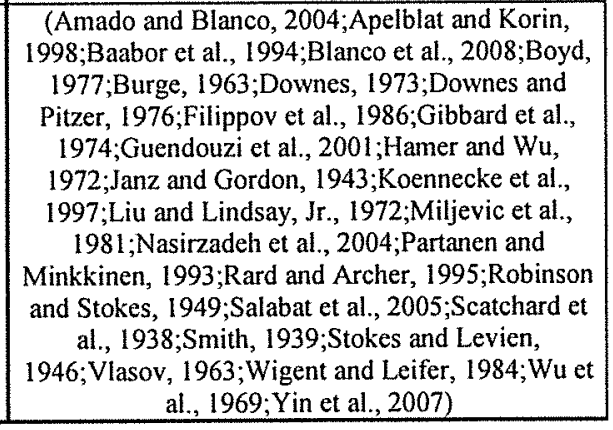 \\
\hline
\end{tabular}

Experimental vapor pressures are reproduced with an AAD of $2.7 \%$ for temperatures up to 673 $\mathrm{K}$ and $\mathrm{NaCl}$ salinity up to 7.8 molal. Evolutions with temperature of the ratios of brine saturation vapor pressure over pure water vapor pressure are illustrated in Figure 1 for different salinities. The top first dotted line shows the deviation between pure water vapor pressure predicted by eCPA model and the representation from the DIPPR correlation (Rowley et al., 2011) up to the water critical point. Thereafter the decrease of vapor pressure while increasing salinity shown by the experimental data is well represented by the model particularly at moderate temperatures. 


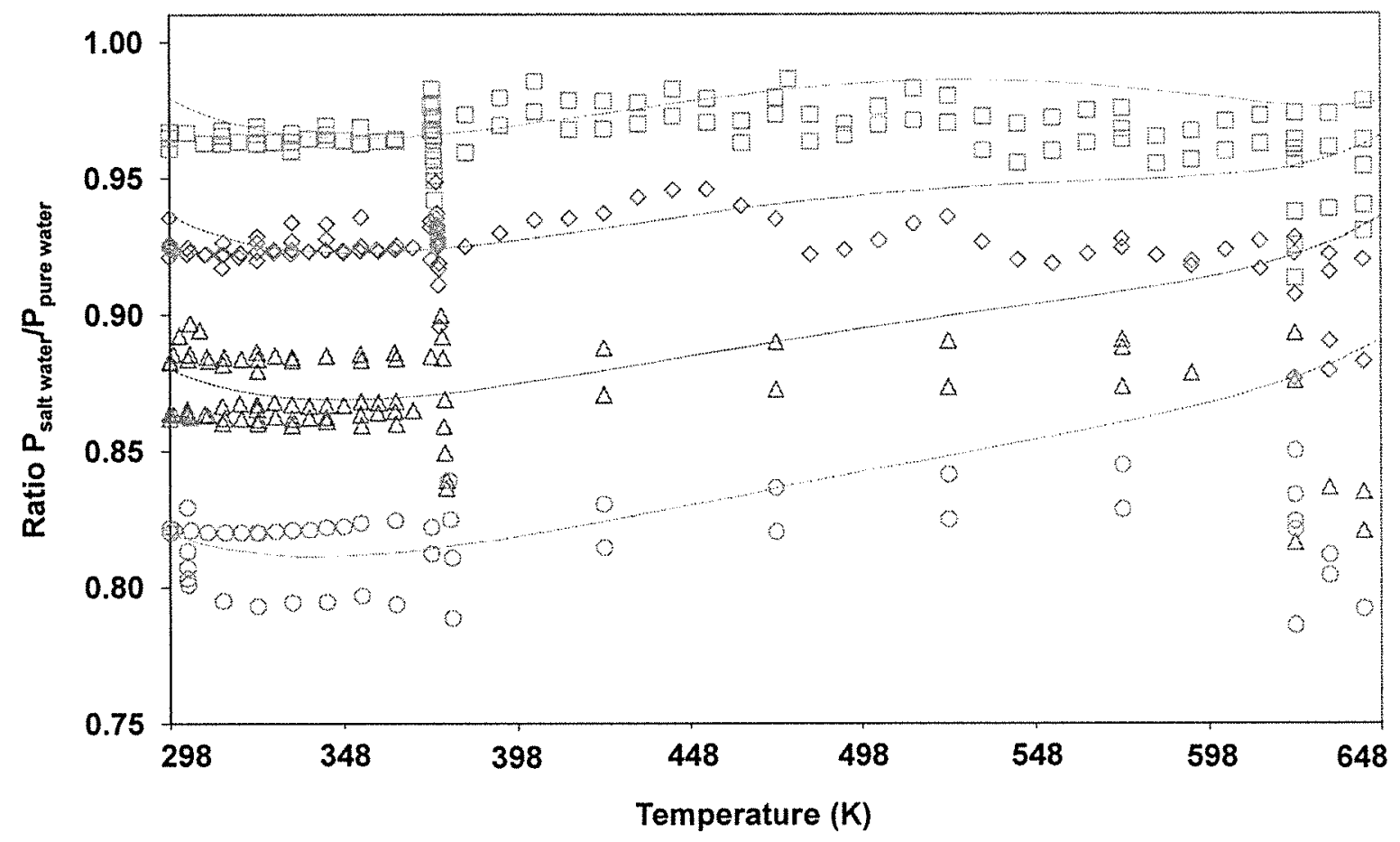

Figure 1. Influence with temperature of salinity on the brine vapor pressures compared to pure water vapor pressure estimated by the DIPPR reference correlation (Rowley et al., 2011). NaCl molalities: 0.7 $(\mathrm{D}) ; 1.9(\diamond) ; 3.4(\triangle)$ and $4.9(\bigcirc)$. Symbols are experimental data. Lines are the model representations.

Experimental molar volumes at and out of saturation up to 5.7 molal of $\mathrm{NaCl}$ are represented respectively with an $\mathrm{AAD}$ of $4.6 \%$ for temperatures up to $713 \mathrm{~K}$ and of $4.0 \%$ for temperatures and pressures up to $773 \mathrm{~K}$ and $400 \mathrm{MPa}$. Generally, molar volumes are worst represented at temperatures higher than water critical temperature together with pressures below $100 \mathrm{MPa}$.

Experimental water osmotic coefficients are represented with an $\mathrm{AAD}$ of $2.5 \%$ for $\mathrm{NaCl}$ salinity up to 10 molal and temperatures as high as $573 \mathrm{~K}$. Experimental determination of $\mathrm{NaCl}$ mean ionic activity coefficients are also available up to $573 \mathrm{~K}$ for $\mathrm{NaCl}$ salinity up to 6.7 molal. These last data are represented with an AAD of $3 \%$ and are illustrated in Figure 2. Both salinity and temperature effects are quite well represented by the eCPA model. 


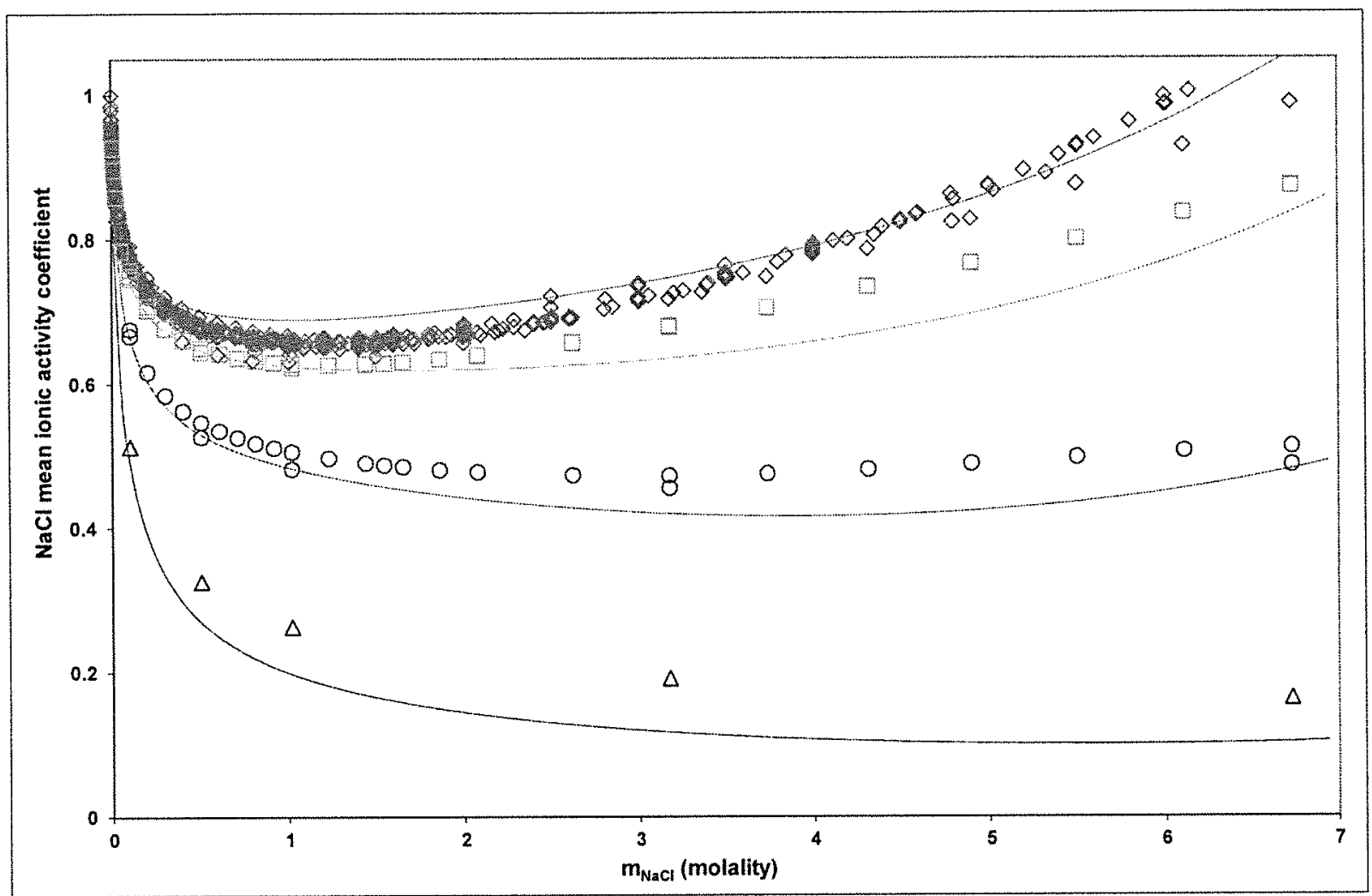

Figure 2. Evolution with $\mathrm{NaCl}$ molality of the $\mathrm{NaCl}$ mean ionic activity coefficient at $298 \mathrm{~K}(\diamond) ; 373 \mathrm{~K}$ $(\square) ; 473 \mathrm{~K}(\mathrm{O})$ and $573 \mathrm{~K}(\triangle)$. Symbols are the experimental data. Lines are the model.

\section{5. $\mathrm{CH}_{4}+\mathrm{CO}_{2}, \mathrm{CH}_{4}+\mathrm{H}_{2} \mathrm{O}$ and $\mathrm{CO}_{2}+\mathrm{H}_{2} \mathrm{O}$ systems}

The system $\mathrm{CH}_{4}+\mathrm{CO}_{2}$ is modeled using a binary interaction parameter $\left(k_{i j}\right.$ in equation (3)) equal to 0.0882 . This value is directly taken from literature (Tsivintzelis et al., 2011) and, as shown by these authors, this parameter allows a good reproduction of phase equilibrium and densities of this system.

The systems $\mathrm{CH}_{4}+\mathrm{H}_{2} \mathrm{O}$ and $\mathrm{CO}_{2}+\mathrm{H}_{2} \mathrm{O}$ are particularly difficult to model at high temperature and pressure due to the presence of one (liquid-vapor) or even two (liquid-vapor and liquid-liquid) critical points, as illustrated on Figure 3 and Figure 4. 


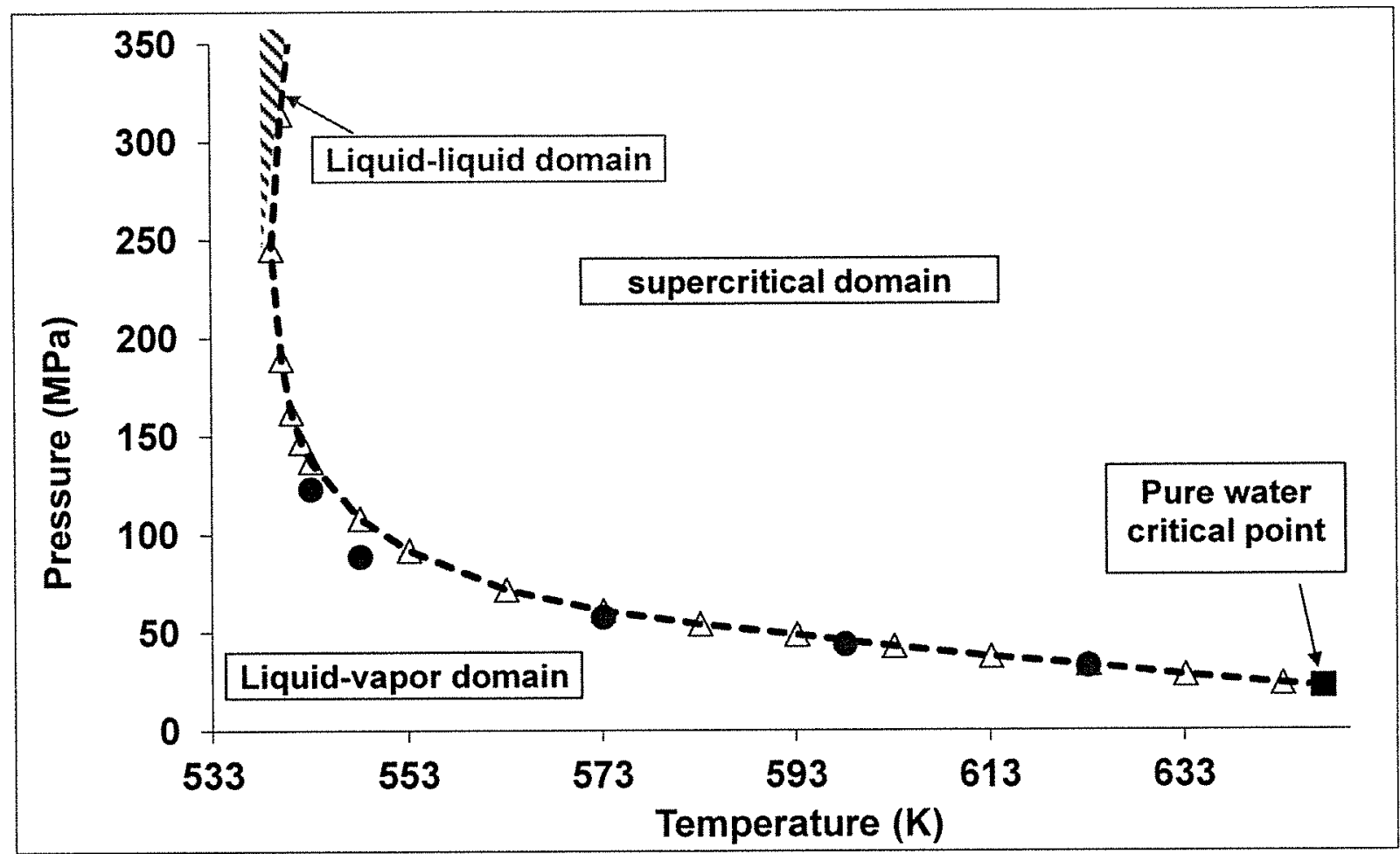

Figure 3. Locations of critical points in the $\mathrm{CO}_{2}+\mathrm{H}_{2} \mathrm{O}$ system. Symbols are the experimental critical points (filled circles: Takenouchi et al. (Takenouchi and Kennedy, 1964); open triangles: Todheide et al. (Todheide and Franck, 1963)). The dotted line is a guide for the eyes. The hachured area stands for the liquid-liquid domain.

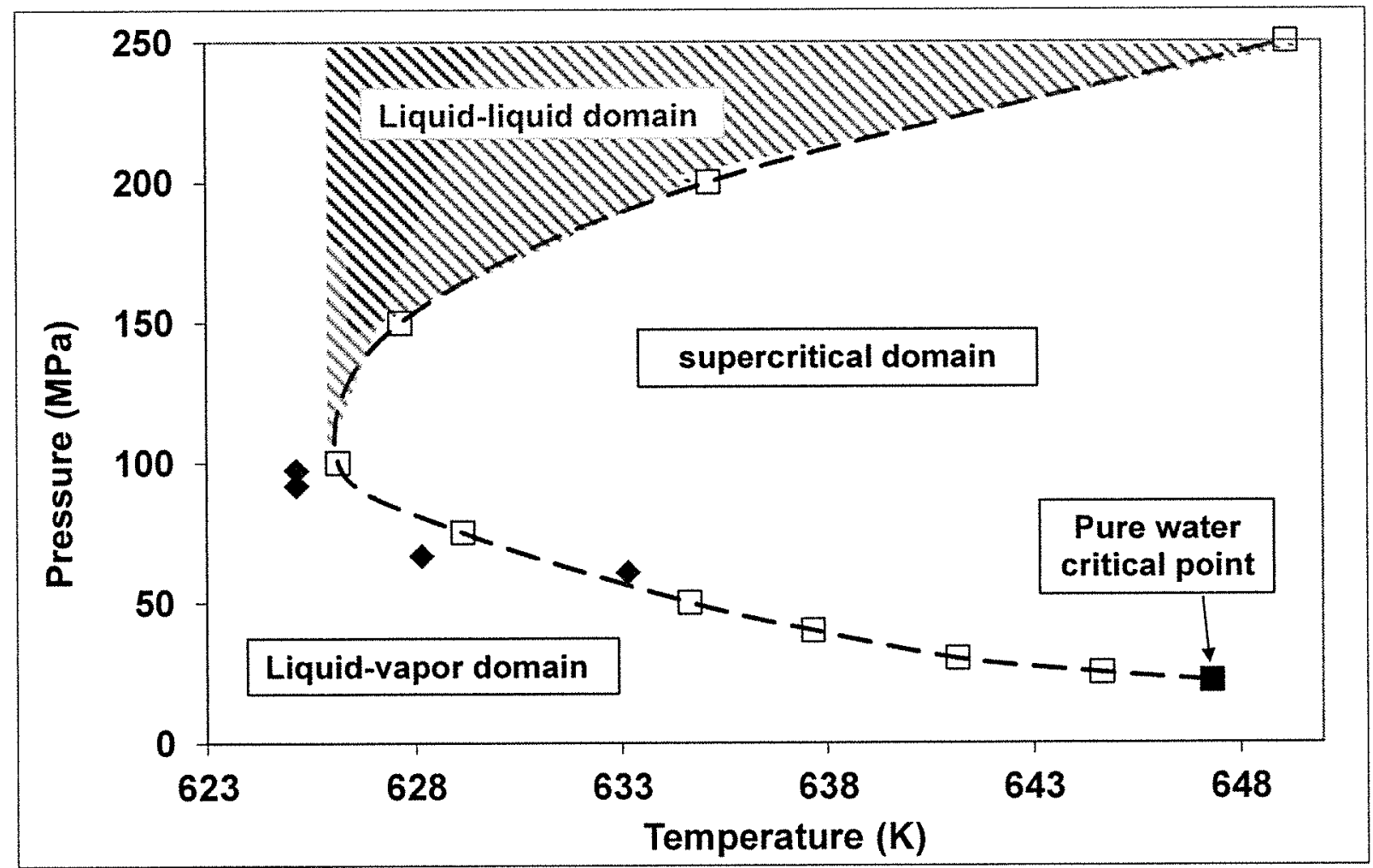

Figure 4. Locations of critical points in the $\mathrm{CH}_{4}+\mathrm{H}_{2} \mathrm{O}$ system. Symbols are the experimental critical points (filled diamonds: Sultanov et al.(Sultanov et al., 1971;Sultanov, 1972); open squares: Welsch (Welsch, 1973)). The dotted line is a guide for the eyes. The hatched area stands for the liquid-liquid domain. 
For the $\mathrm{CH}_{4}+\mathrm{H}_{2} \mathrm{O}$ system, the liquid-vapor critical points appear for a temperature and pressure of $626 \mathrm{~K}$ and $97.3 \mathrm{MPa}$, and finish at the critical point of pure water $(647 \mathrm{~K}, 22.06 \mathrm{MPa})$. Below the temperature of $626 \mathrm{~K}$, the system exhibits a two-fluid phase equilibrium without critical point. The experimental data of Welsch (Welsch, 1973) also exhibit the existence of liquid-liquid critical points for temperatures and pressures above $626 \mathrm{~K}$ and $100 \mathrm{MPa}$. A liquid-liquid phase equilibrium domain is thus determined for temperatures and pressures above the liquid-liquid critical point line. The system is single phase for temperatures and pressures between the liquid-liquid critical point line and the liquid-vapor critical point line. The $\mathrm{CO}_{2}+\mathrm{H}_{2} \mathrm{O}$ system behaves similarly. It can however be noticed that the liquid-liquid critical point line appears for higher pressures (above $250 \mathrm{MPa}$ ), and the minimal temperature for which a liquid-vapor critical point exists is close to $538 \mathrm{~K}$. For both systems, only a very limited number of experimental data are available for the high pressure liquid-liquid equilibrium and the location of the liquid-liquid critical points. Consequently, we only focus in this work on the modeling of the liquid-vapor phase equilibrium.

Without binary interaction parameters, large deviations are often observed in phase equilibrium predictions for the binary systems with $\mathrm{H}_{2} \mathrm{O}$. More specifically, critical points are not correctly predicted. Thus, binary interaction parameters are required to better represent the experimental liquidvapor phase equilibrium data of the binary systems $\mathrm{CH}_{4}+\mathrm{H}_{2} \mathrm{O}$ and $\mathrm{CO}_{2}+\mathrm{H}_{2} \mathrm{O}$. These parameters have been fitted to (1) reproduce the gas solubility in the aqueous phase and (2) to represent the phase envelope closure at the appearance of the mixture critical point. Note that for these systems, no volumetric data have been used in the parameter regression. The phase densities given by the model are thus obtained in pure prediction. We also recall that the liquid-liquid domain is not considered in this work. The number of experimental gas solubility data and the temperature and pressure range used to fit the binary interaction parameters are given in Table 5. The temperature and pressure ranges are taken as large as possible to ensure a good extrapolation of the model. However, experimental data at high temperature / high pressure are pondered with a more important weight, as we focus in this work more specifically on these specific conditions.

Table 5. Experimental gas solubility data used for binary interaction parameter regression.

\begin{tabular}{|c|c|c|c|c|c|}
\hline System & $n$ data & $\begin{array}{c}\text { Temperature } \\
\text { range }\end{array}$ & Pressure range & $\begin{array}{c}\text { Salinity } \\
\text { max. } \\
\text { (molality) }\end{array}$ & Ref. \\
\hline $\mathrm{CH}_{4}+\mathrm{H}_{2} \mathrm{O}$ & 1061 & {$[253 ; 623 \mathrm{~K}]$} & {$[0.1 ; 250 \mathrm{MPa}]$} & - & $\begin{array}{l}\text { (Addicks et al., 2002;Carroll, } \\
\text { 1998;Chapoy et al., } \\
\text { 2003;Chapoy et al., } \\
\text { 2004b;Culberson, } \\
\text { 1951;Culberson and McKetta, } \\
\text { 1950;Davis and McKetta, } \\
\text { 1960;Dhima, 1998;Duffy et al., } \\
\text { 1961;Folas et al., 2007;Gillespie } \\
\text { and Wilson, 1982;Kiepe et al., } \\
\text { 2003b;Kim et al., 2003;Lekvam } \\
\text { and Bishnoi, 1997;Michels et al., } \\
\text { 1936;Olds et al., 1942;Rigby } \\
\text { and Prausnitz, 1968;Sanchez and } \\
\text { de Meer, 1978;Sharma, } \\
\text { 1969;Siqueira Campos et al., } \\
\text { 2010;Sultanov et al., } \\
\text { 1971;Sultanov, }\end{array}$ \\
\hline
\end{tabular}




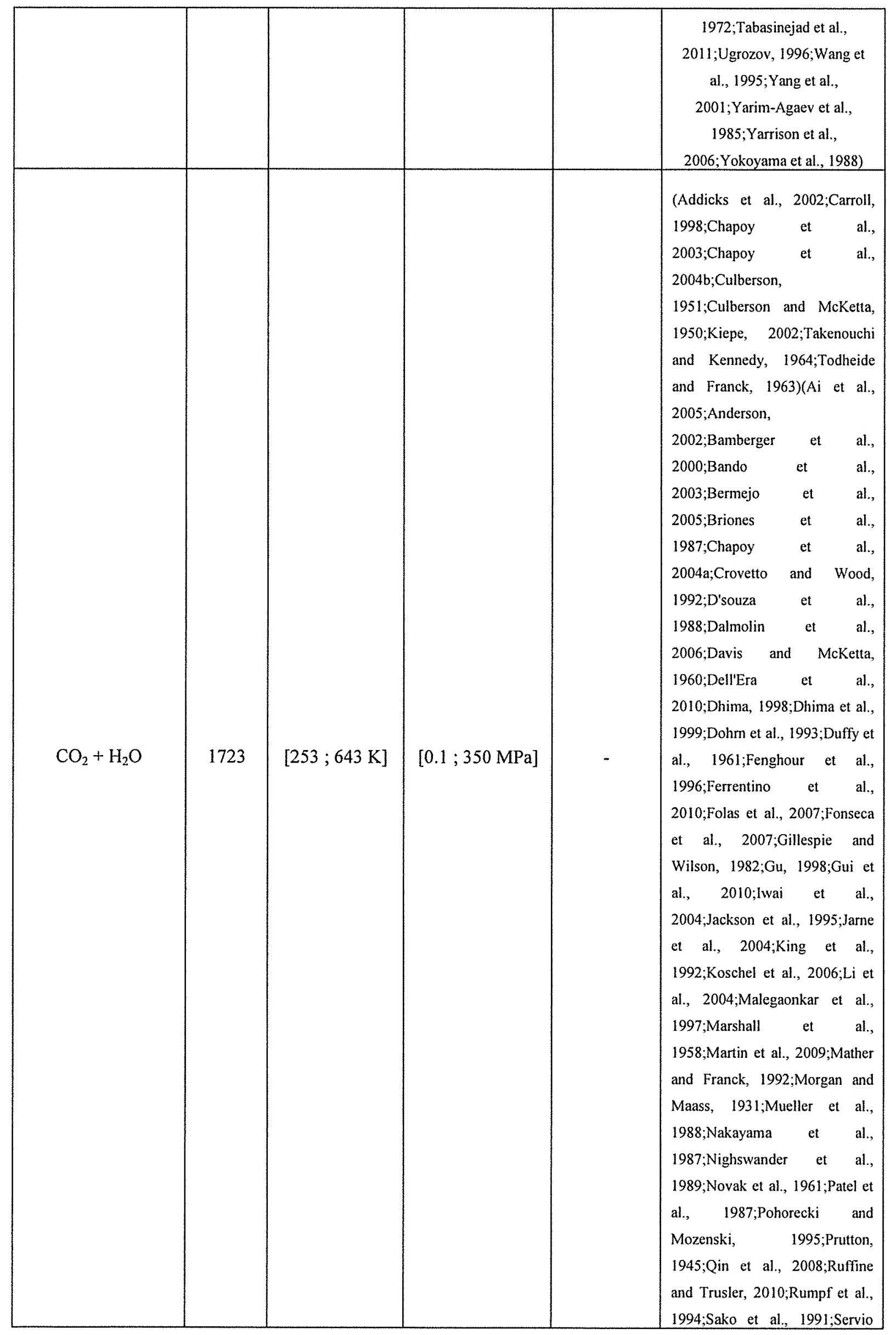




\begin{tabular}{|c|c|c|c|c|c|}
\hline & & & & & 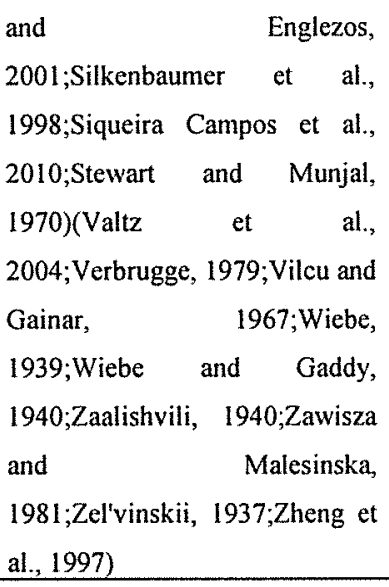 \\
\hline $\mathrm{CH}_{4}+\mathrm{H}_{2} \mathrm{O}+\mathrm{NaCl}$ & 599 & {$[273 ; 573 \mathrm{~K}]$} & {$[10 ; 150 \mathrm{MPa}]$} & 6 & $\begin{array}{l}\text { (Blount, 1980;Cramer, } \\
\text { 1982;McGee et al., } \\
\text { 1981;O'Sullivan, 1970) }\end{array}$ \\
\hline $\mathrm{CO}_{2}+\mathrm{H}_{2} \mathrm{O}+\mathrm{NaCl}$ & 509 & {$[277 ; 723 \mathrm{~K}]$} & {$[1 ; 140 \mathrm{MPa}]$} & 6 & $\begin{array}{l}\text { (Bando et al., 2003;Ferrentino et } \\
\text { al., 2010;Gu, 1998;Kiepe, } \\
\text { 2002;Koschel et al., 2006;Li and } \\
\text { Tsui, 1971;Malinin and } \\
\text { Kurovskaya, 1975;Malinin and } \\
\text { Savelyeva, 1972;Nighswander et } \\
\text { al., 1989;Rumpf et al., } \\
\text { 1994;Takenouchi and Kennedy, } \\
\text { 1965) }\end{array}$ \\
\hline
\end{tabular}

In a first step, the binary interaction parameter is fitted individually for each temperature. That allows to plot its trend with temperature, as shown on Figure 5 and Figure 6 for the systems $\mathrm{CH}_{4}+$ $\mathrm{H}_{2} \mathrm{O}$ and $\mathrm{CO}_{2}+\mathrm{H}_{2} \mathrm{O}$, respectively.

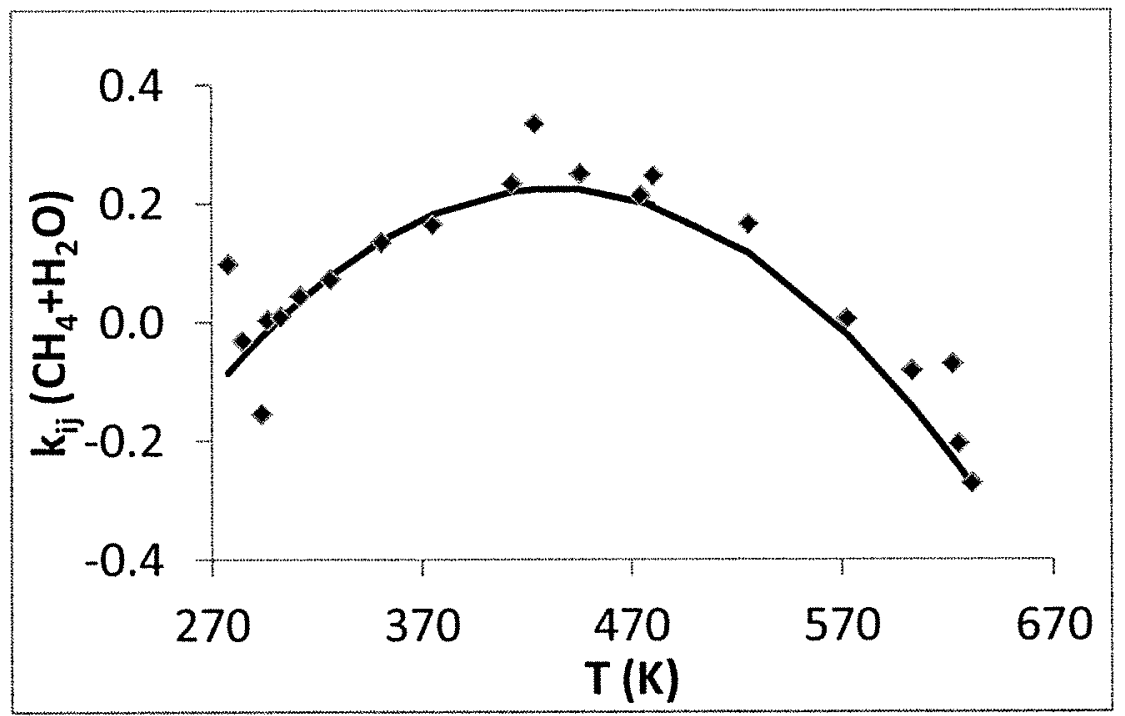

Figure 5. Binary interaction parameters for the $\mathrm{CH}_{4}+\mathrm{H}_{2} \mathrm{O}$ system. Symbols: optimized values for each temperatures. Line: fit of the optimized values (equation (22)). 


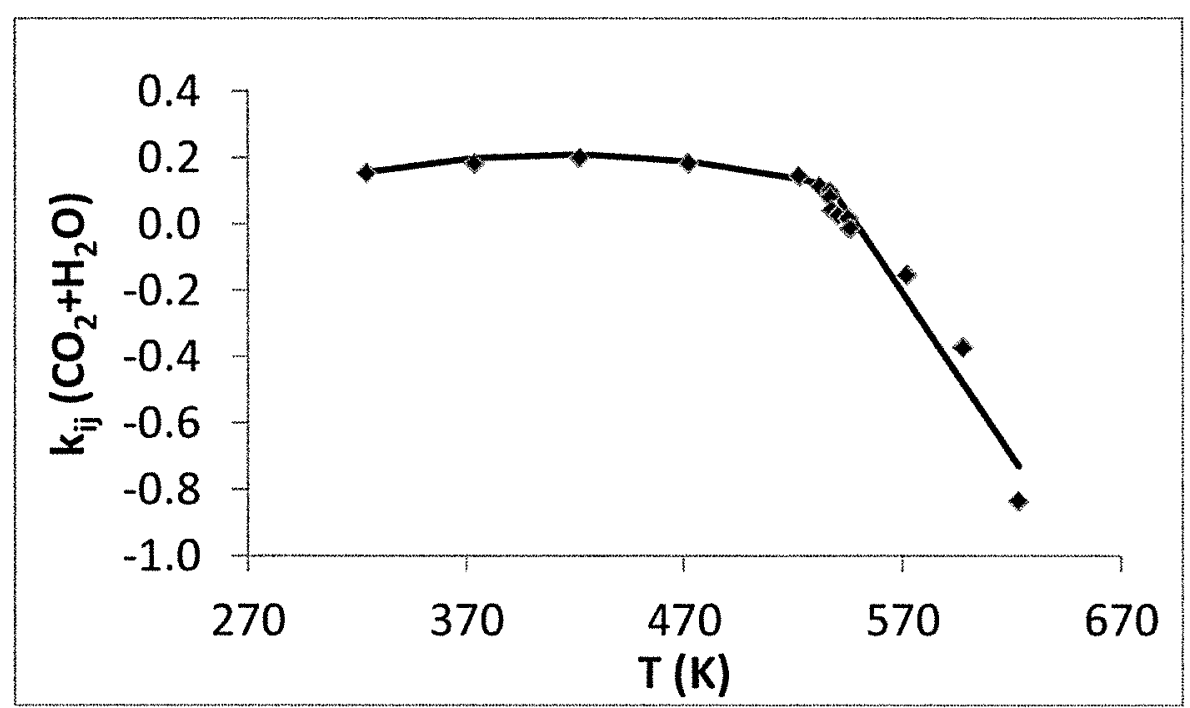

Figure 6. Binary interaction parameters for the $\mathrm{CO}_{2}+\mathrm{H}_{2} \mathrm{O}$ system. Symbols: optimized values for each temperatures. Line: fit of the optimized values (equation (22)).

The optimized binary parameters for the $\mathrm{CH}_{4}+\mathrm{H}_{2} \mathrm{O}$ system exhibit a parabolic trend. This is why in a second step, a second order temperature dependency is proposed for this parameter:

$$
k_{i j}(T)=k_{i j}^{0}+k_{i j}^{1} \cdot T+k_{i j}^{2} \cdot T^{2}
$$

Where $T$ is the temperature in $\mathrm{K}$. The parameters $k_{i j}^{0}, k_{i j}^{1}$ and $k_{i j}^{2}$ are given in Table 6.

The optimized parameters for the $\mathrm{CO}_{2}+\mathrm{H}_{2} \mathrm{O}$ system show two distinct trends: below $537 \mathrm{~K}$ (temperature for which the critical point appears), moderate values are obtained (between 0 and 0.2 ), and they are fitted with a second-order temperature dependency. For temperature above $537 \mathrm{~K}$, the values of $k_{i j}$ drastically decrease, and become largely negative (up to -0.8). Such very high negative values for this parameter is a consequence of the strong attraction of water and $\mathrm{CO}_{2}$ in this temperature range where critical points are present. The optimized $k_{i j}$ are fitted in this domain with a first-order temperature dependency. The same approach is followed for the other binary systems investigated. Table 6 shows the parameters determined for equation (22) for each system. These binary interaction parameters are found to be a good compromise to reproduce simultaneously gas solubility in water, critical point appearance, and phase density.

Table 6. Binary interaction parameters for the eCPA model

\begin{tabular}{|c|c|c|c|c|}
\hline System & $\begin{array}{l}\text { VLE data range } \\
(\mathrm{K})\end{array}$ & $k_{i j}^{0}$ & $k_{i j}^{1}$ & $k_{i j}^{2}$ \\
\hline $\begin{array}{c}\mathrm{CH}_{4}+\mathrm{CO}_{2} \\
\text { (Tsivintzelis et al., } \\
2011 \text { ) }\end{array}$ & $219-301$ & 0.08820 & 0 & 0 \\
\hline $\mathrm{CH}_{4}+\mathrm{H}_{2} \mathrm{O}$ & $283-663$ & -2.18100 & 0.01111 & $-1.27902 \cdot 10^{-5}$ \\
\hline \multirow{2}{*}{$\mathrm{CO}_{2}+\mathrm{H}_{2} \mathrm{O}$} & $323-537$ & $-9.12960 \cdot 10^{-1}$ & $5.40410 \cdot 10^{-3}$ & $-6.49667 \cdot 10^{-6}$ \\
\hline & $537-623$ & 5.39448 & $-9.82899 \cdot 10^{-3}$ & - \\
\hline $\mathrm{CH} 4+[\mathrm{Na}+$ and $\mathrm{Cl}-]$ & $286-563$ & 1.47532 & $-7.33268 \cdot 10^{-3}$ & - \\
\hline $\mathrm{CO} 2+[\mathrm{Na}+$ and $\mathrm{Cl}-]$ & $298-673$ & 0.40050 & $2.24613 \cdot 10^{-3}$ & $-1.40671 \cdot 10^{-5}$ \\
\hline
\end{tabular}


Figure 7 presents experimental and calculated pressure-composition diagrams for $\mathrm{CH}_{4}+\mathrm{H}_{2} \mathrm{O}$ binary system from 373 to $633 \mathrm{~K}$. Trends shown by the liquid-vapor equilibrium data are fairly well reproduced by the model in the entire range of temperature, even if the critical pressure of the mixture is slightly over predicted as well as methane solubility. Molar volumes are generally well represented for this system and only conditions in the continuity of pure water critical coordinates are also not well represented, viz. for temperatures close and above pure water critical temperature for high $\mathrm{H}_{2} \mathrm{O}$ content.

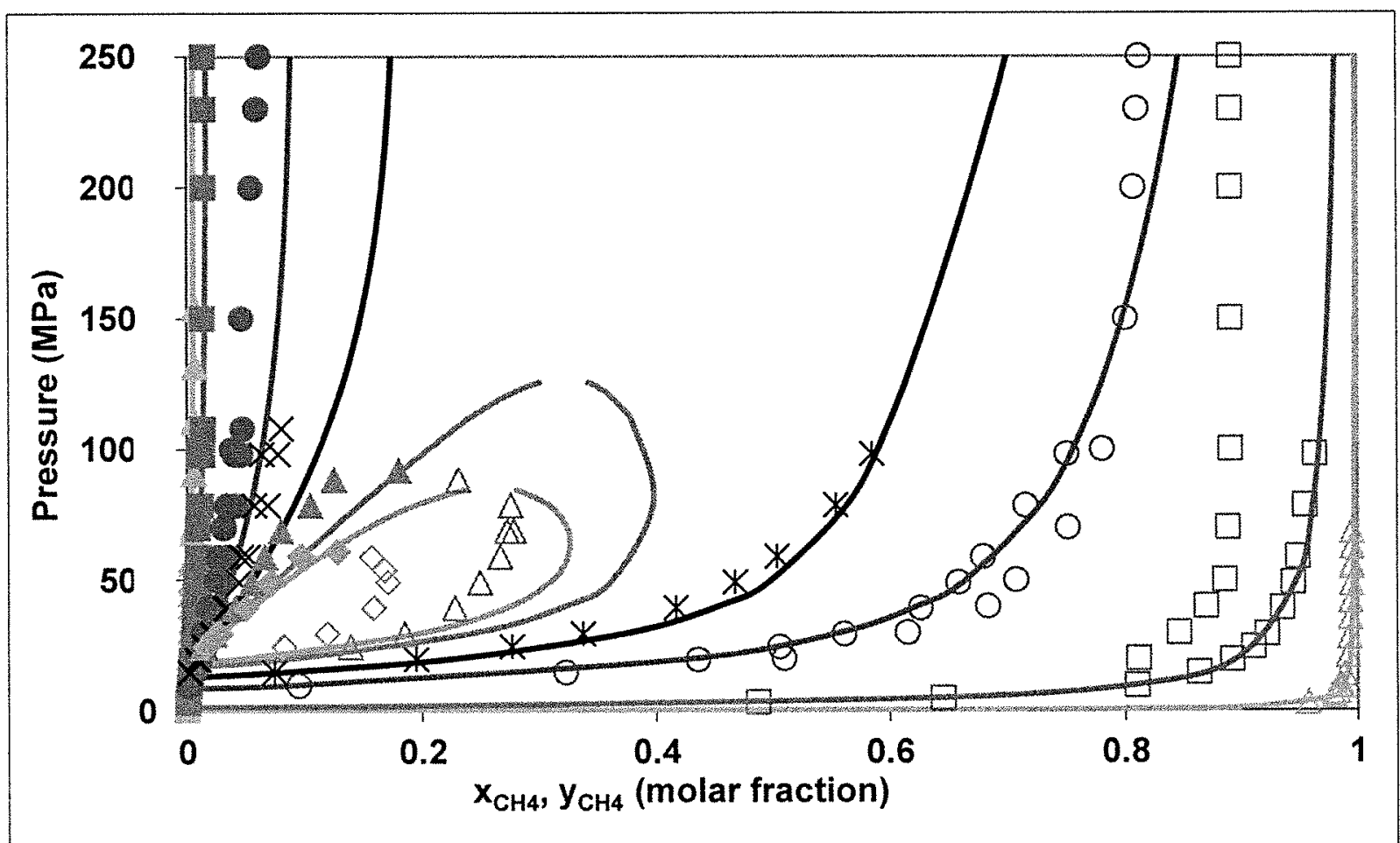

Figure 7. VLE for $\mathrm{CH}_{4}(1)+\mathrm{H}_{2} \mathrm{O}(2)$ binary system at $373 \mathrm{~K}(\triangle), 473 \mathrm{~K}(\square), 573 \mathrm{~K}(0), 603 \mathrm{~K}(*), 625 \mathrm{~K}$ $(\diamond)$ and $633 \mathrm{~K}(\Delta)$. Empty symbols refer to experimental vapor phase composition $\left(y_{C H 4}\right)$ while full symbols refer to experimental liquid phase composition $\left(x_{C H 4}\right)$. Lines are the model representations.

Experimental and calculated liquid-vapor equilibrium for the $\mathrm{CO}_{2}+\mathrm{H}_{2} \mathrm{O}$ binary system are shown in Figure 8 between 373 and $623 \mathrm{~K}$. Even if increasing the cross-association strength between $\mathrm{CO}_{2}$ and $\mathrm{H}_{2} \mathrm{O}$ (using a larger association volume for $\mathrm{CO}_{2}$ ) has improved the VLE representation for the binary system, it is still not sufficient to well reproduce both liquid and vapor composition at high temperature. As a consequence, $\mathrm{CO}_{2}$ liquid phase composition is well reproduced, but $\mathrm{CO}_{2}$ vapor phase compositions are over predicted by the model at 473 and $533 \mathrm{~K}$. It is worth noticing that experimental data for vapor phase composition are very scarce in literature at high temperature. More specifically at $533 \mathrm{~K}$, two experimental data sets are available (Takenouchi and Kennedy, 1964; Todheide and Franck, 1963) but are not really consistent. The acquisition of new experimental data would be useful for modeling this system in such extreme conditions. Although not included in the regression parameter database, molar volumes are generally well represented for this system but in the same way as observed with $\mathrm{CH}_{4}+\mathrm{H}_{2} \mathrm{O}$ system, the model fails to reproduce accurately molar volumes particularly at temperatures close and above water critical temperature for high $\mathrm{H}_{2} \mathrm{O}$ content. 


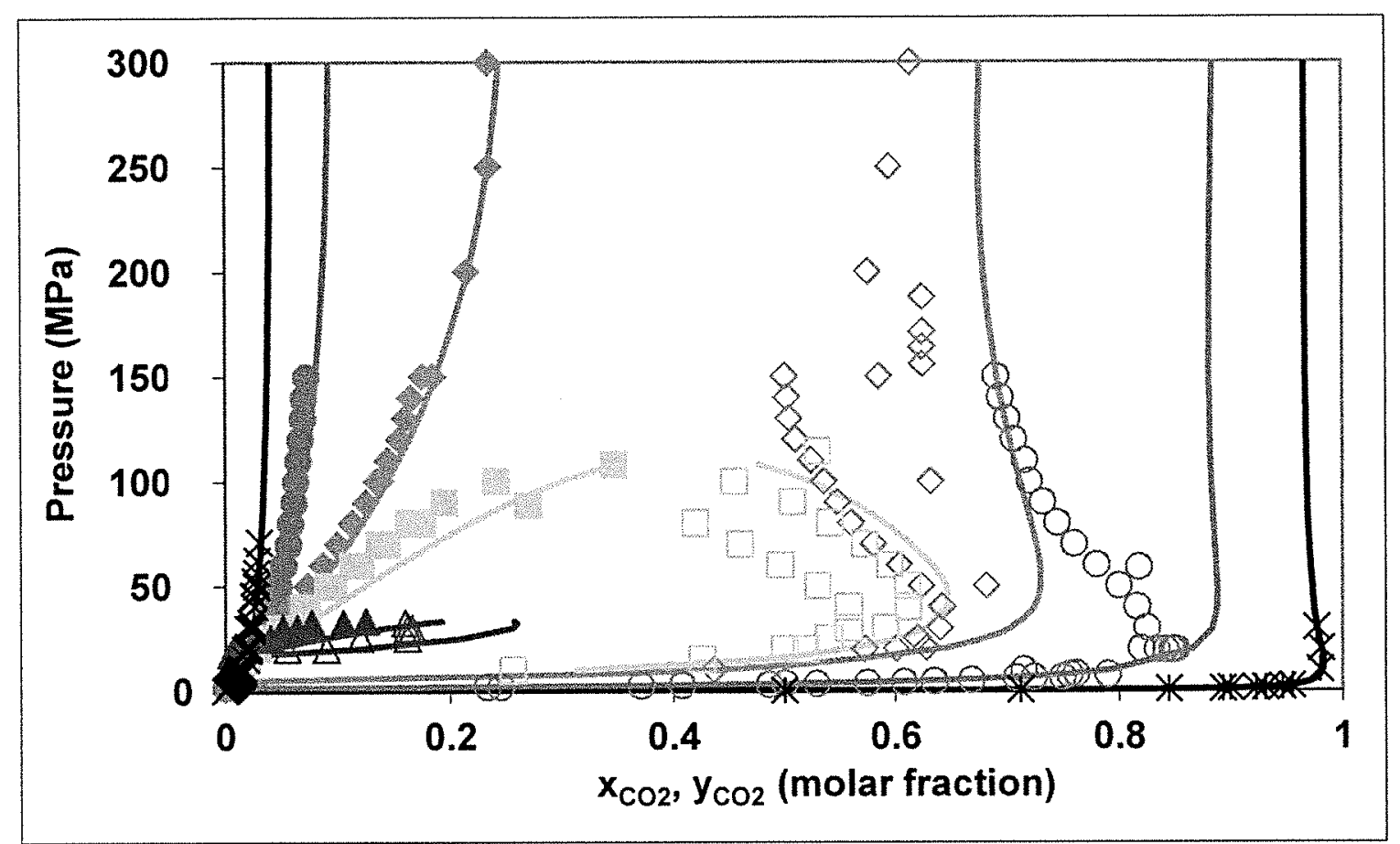

Figure 8. VLE for $\mathrm{CO}_{2}(1)+\mathrm{H}_{2} \mathrm{O}(2)$ binary system at $373 \mathrm{~K}(*), 473 \mathrm{~K}(\mathrm{O}), 533 \mathrm{~K}(\diamond), 548 \mathrm{~K}(\mathrm{)})$ and $623 \mathrm{~K}(\triangle)$. Empty symbols refer to experimental vapor phase composition $\left(y_{\mathrm{CO} 2}\right)$ while full symbols refer to experimental liquid phase composition $\left(x_{\mathrm{CO} 2}\right)$. Lines are the model representations.

Table 7 presents deviations between experimental data and model description for liquid-vapor phase equilibrium (liquid and vapor phase composition) and molar volumes $\left(V_{m}\right)$ out of saturation for the binary systems studied.

Table 7. AAD (\%) between experimental data and model description using eCPA equation of state for liquid-vapor equilibrium (VLE) and molar volumes for binary systems.

\begin{tabular}{|c|c|c|c|}
\hline System & $x_{l}(\mathrm{AAD} \%)$ & $y_{l}(\mathrm{AAD} \%)$ & $V_{m}(\mathbf{A A D} \%)$ \\
\hline $\begin{array}{c}\mathrm{CH}_{4}(1)+\mathrm{CO}_{2}(2) \\
\text { (Tsivintzelis et al., 2011) }\end{array}$ & 6 & 9 & 1.7 \\
\hline $\mathrm{CH}_{4}(1)+\mathrm{H}_{2} \mathrm{O}$ (2) (this work) & 16 & 8 & 2.6 \\
\hline $\mathrm{CO}_{2}(1)+\mathrm{H}_{2} \mathrm{O}$ (2) (this work) & 26 & 12 & 2.8 \\
\hline
\end{tabular}

The CPA-family equation of state has already proved its ability to be extended to multicomponent systems from parameterizations carried out on binary systems only. As an example for this application, co-solubility data of Qin et al. (Qin et al., 2008) for the ternary system $\mathrm{CH}_{4}+\mathrm{CO}_{2}+\mathrm{H}_{2} \mathrm{O}$ at $375 \mathrm{~K}$ are correctly represented using only the binary interaction parameters of Table 6 . Deviations on vapor pressures and vapor phase composition between experiments and model predictions are reported in Table 8 and shown in Figure 9. The highest deviations are found to predict water molar fraction in the vapor phase where experimental values are very low (about 0.02 ). It can be concluded here that the VLE behavior is well predicted by the eCPA model, showing its ability to be extended to multi-component mixtures with only binary interaction parameters. 
Table 8. AAD (\%) between prediction using eCPA equation of state and experimental data for vapor pressure and vapor phase composition in the $\mathrm{CH}_{4}+\mathrm{CO}_{2}+\mathrm{H}_{2} \mathrm{O}$ ternary system at $375 \mathrm{~K}$.

\begin{tabular}{|c|c|c|c|}
\hline Vapor pressure & $y_{\mathrm{CH} 4}$ & $y_{\mathrm{CO} 2}$ & $y_{\mathrm{H} 2 \mathrm{O}}$ \\
\hline $5.6 \%$ & $2.9 \%$ & $3.0 \%$ & $35.1 \%$ \\
\hline
\end{tabular}

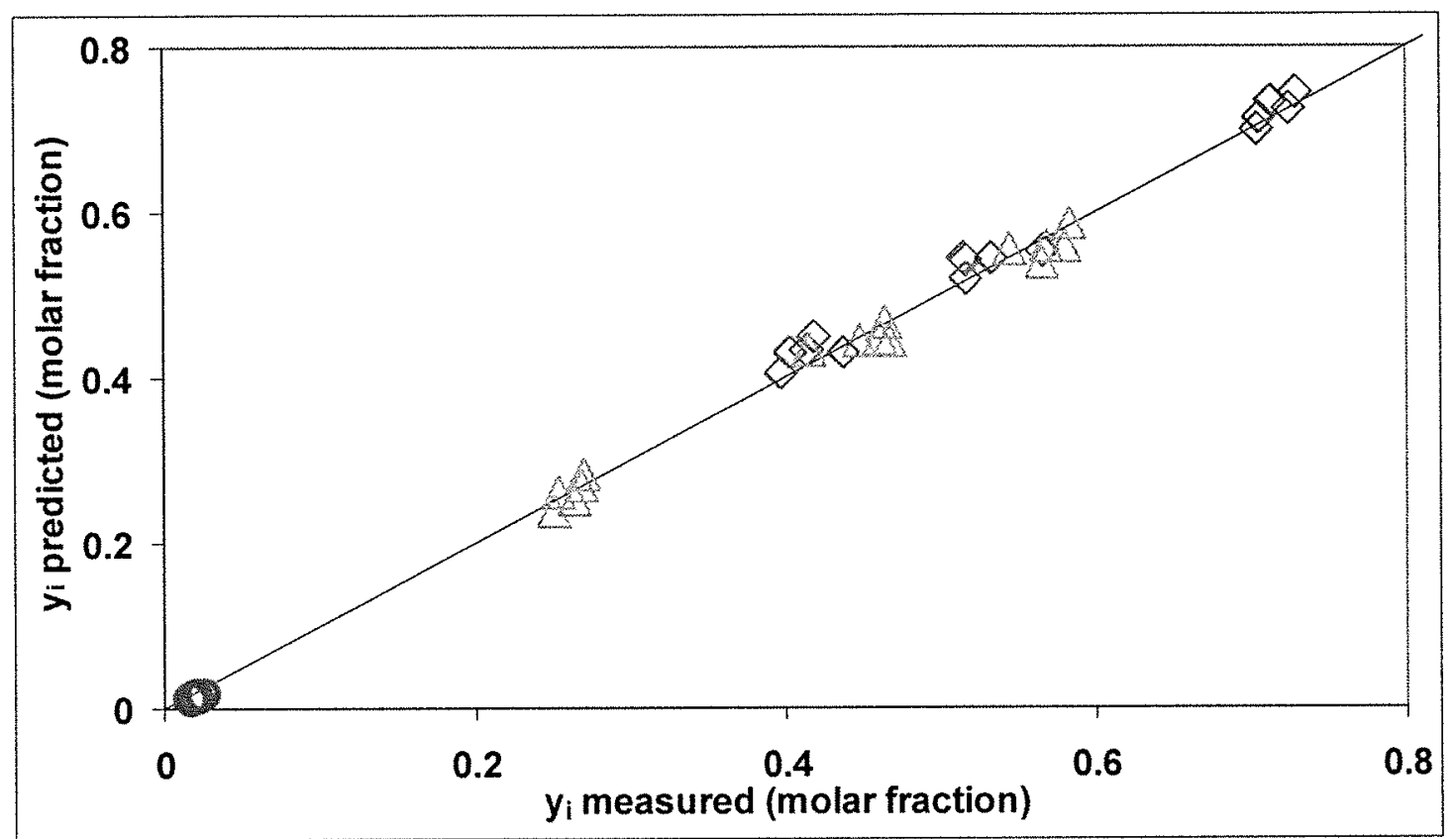

Figure 9. Comparison between experimental and predicted vapor phase composition for the $\mathrm{CH}_{4}+\mathrm{CO}_{2}+$ $\mathrm{H}_{2} \mathrm{O}$ ternary system at $375 \mathrm{~K} . \mathrm{y}_{\mathrm{CH} 4}(\Delta) ; \mathrm{y}_{\mathrm{CO} 2}(\diamond)$; and $\mathrm{y}_{\mathrm{H} 2 \mathrm{O}}(\mathrm{O})$.

\section{6. $\mathrm{CH}_{4}+\mathrm{H}_{2} \mathrm{O}+\mathrm{NaCl}$ and $\mathrm{CO}_{2}+\mathrm{H}_{2} \mathrm{O}+\mathrm{NaCl}$ systems}

The addition of electrolytes in an aqueous solution is known to reduce the gas solubility ("saltingout" effect). A consequence is the disappearance or the displacement of the mixture critical point to higher temperature and pressure than for a salt-free solution. In order to reproduce such a behavior, it is necessary to introduce in the model binary interaction parameter between the light gas molecule $\left(\mathrm{CH}_{4}\right.$ or $\left.\mathrm{CO}_{2}\right)$ and the ions $\left(\mathrm{Na}^{+}\right.$and $\left.\mathrm{Cl}^{-}\right)$. These parameters have been fitted in this work to reproduce the gas solubility for a large range of temperatures, pressures and salinities. No volumetric data have been included in the parameter regression database. The phase densities of these systems are thus obtained in pure prediction. The gas solubility experimental data and conditions used for this optimization are given in Table 5. The optimized parameters are reported in Table 6.

As illustrated on Figure 10, the salting out effect observed for the $\mathrm{CH}_{4}+\left(\mathrm{H}_{2} \mathrm{O}+\mathrm{NaCl}\right)$ pseudobinary system is correctly predicted by the eCPA model. This figure compares experimental and calculated $\mathrm{CH}_{4}$ solubility at $408 \mathrm{~K}$ for $\mathrm{NaCl}$ salinity ranging from 0 to 5.6 molal. Although at this temperature methane solubility is very low, the model reproduces correctly experiments with and without $\mathrm{NaCl}$ for salinities up to about 5 molal. It is worth noticing that no vapor composition data has been found in literature to validate the model predictions. Furthermore, only few density (molar volumes) experimental data have been found for this system. They have all been generated at $800 \mathrm{~K}$ 
for pressures ranging from 10 to $250 \mathrm{MPa}$ and $\mathrm{NaCl}$ salinity between 0.6 and 1.3 molal. At such high temperature, the average deviations are ranging from $10 \%$ at $250 \mathrm{MPa}$ to $50 \%$ at $100 \mathrm{MPa}$.

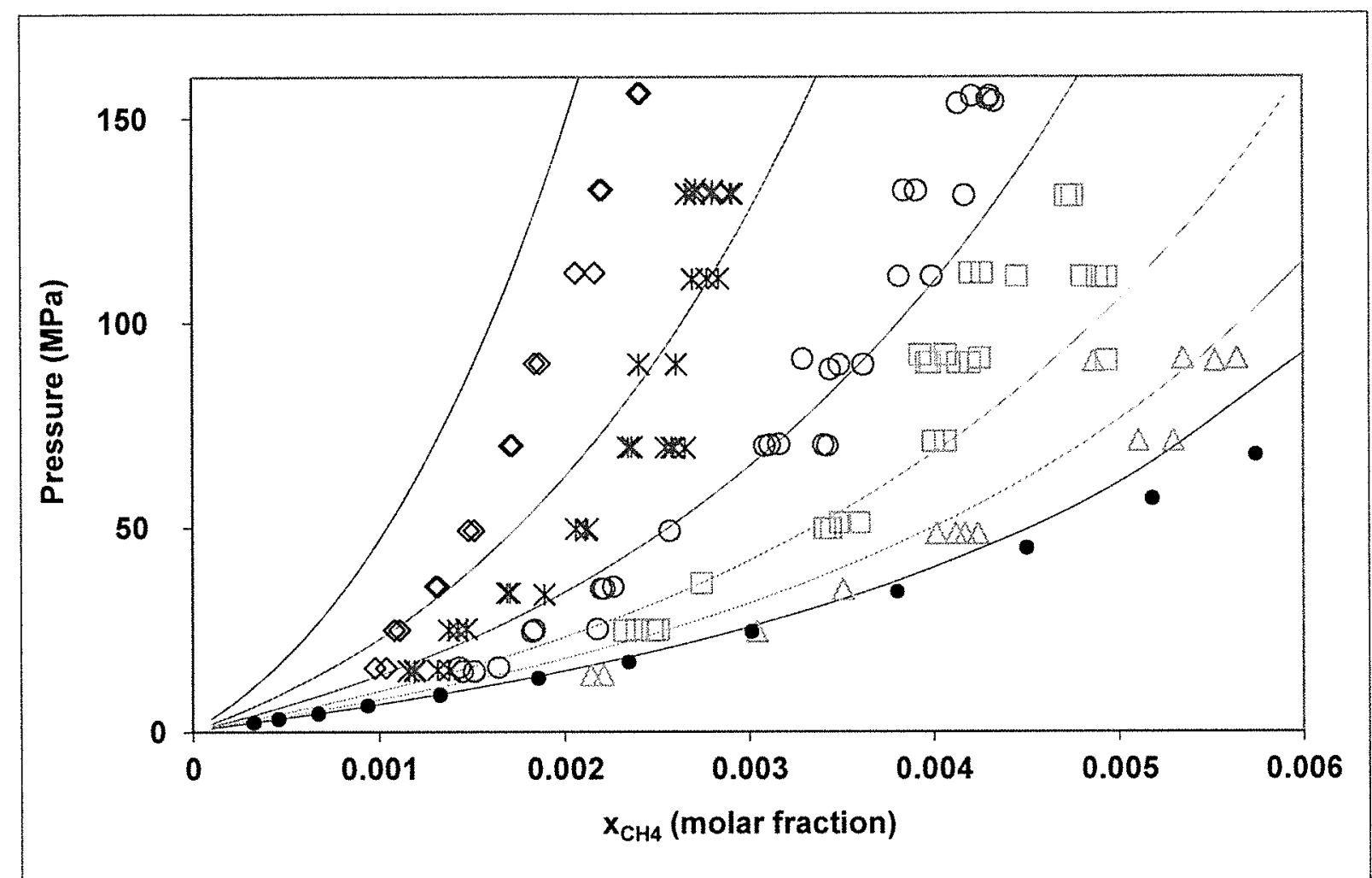

Figure 10. Solubility for $\mathrm{CH}_{4}(1)+\left(\mathrm{H}_{2} \mathrm{O}+\mathrm{Na}^{+}+\mathrm{Cl}\right)$ (2) pseudo-binary system at $408 \mathrm{~K}$ for $\mathrm{NaCl}$ molality $0.00(\bullet) ; 0.86(\Delta) ; 1.8(\square) ; 2.9(O) ; 4.2(*)$ et $5.6(\diamond)$. Symbols are experimental data. Lines are the model representations.

Representations of experimental and calculated phase equilibrium for $\mathrm{CO}_{2}+\left(\mathrm{H}_{2} \mathrm{O}+\mathrm{NaCl}\right)$ pseudo-binary system are shown in Figure 11 at $573 \mathrm{~K}$ for 0 to $3.4 \mathrm{NaCl}$ molality. The salting out effect illustrated by available experimental data is fairly well reproduced here by the model for $\mathrm{NaCl}$ salinities up to 5 molal. Again, no experimental data for vapor phase composition is available in literature. The acquisition of new experimental data would be useful for studying this system in such extreme conditions. Molar volumes are predicted with an average deviation of $28 \%$ for temperatures ranging from 300 to $793 \mathrm{~K}$. The highest deviations (above $40 \%$ ) are observed for pressures close to $50 \mathrm{MPa}$ and for temperatures above $573 \mathrm{~K}$. 


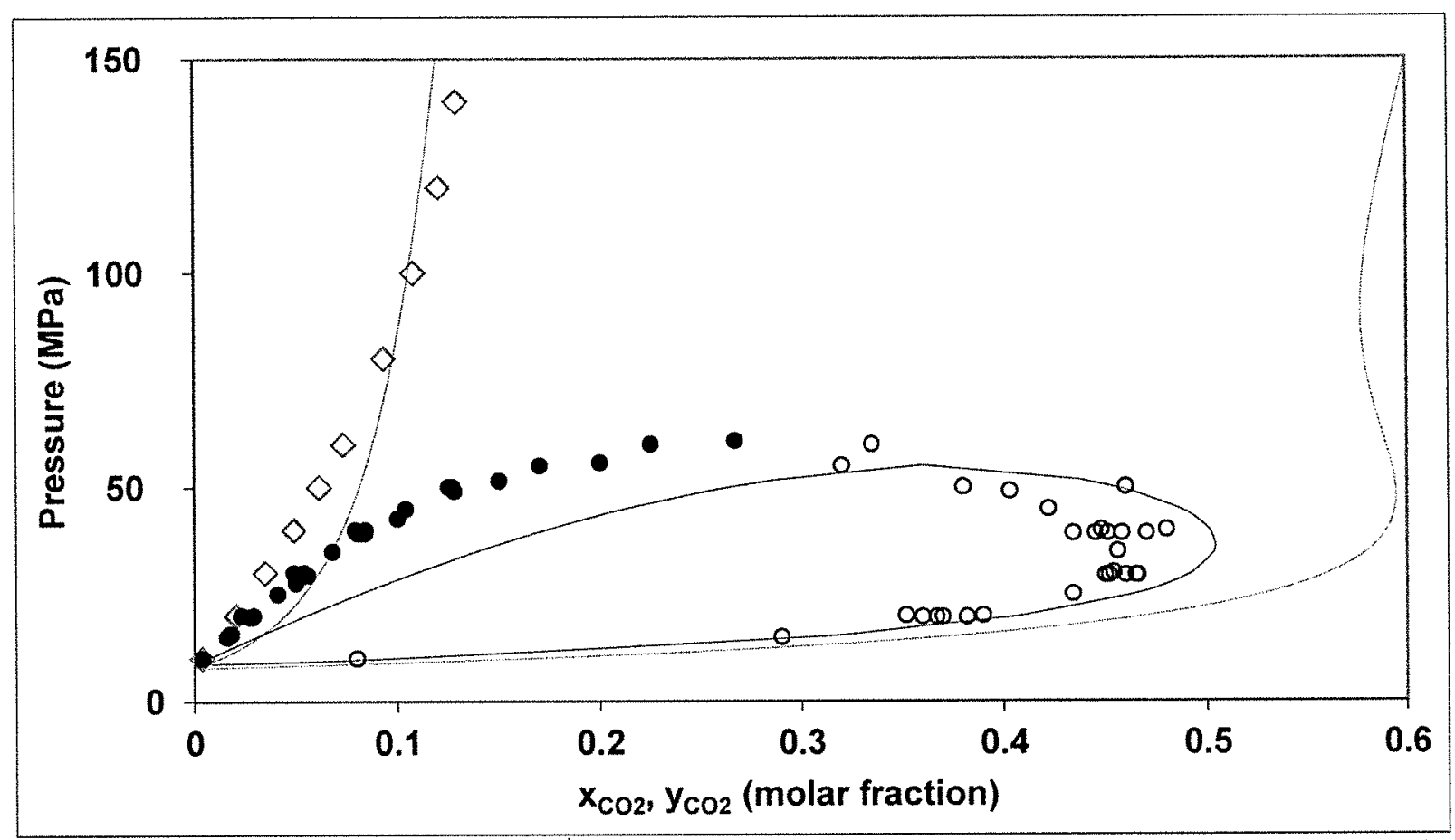

Figure 11. VLE for $\mathrm{CO}_{2}(1)+\left(\mathrm{H}_{2} \mathrm{O}+\mathrm{Na}^{+}+\mathrm{Cl}\right)(2)$ pseudo-binary system at $573 \mathrm{~K}$ for NaCl molality 0.00 $(\bullet)$ and $3.4(\diamond)$. For the system excluding salt, empty symbols refer to experimental vapor phase composition $\left(y_{\mathrm{CO}_{2}}\right)$ while full symbols refer to experimental liquid phase composition $\left(x_{\mathrm{CO} 2}\right)$. Lines are the model representations.

Finally, Table 9 gives the average deviations obtained for the vapor pressure and molar liquid volumes for these salted systems.

Table 9. AAD (\%) between experimental data and model description using eCPA equation of state for liquid-vapor equilibrium (VLE) and molar volumes for $\mathrm{CH}_{4}+\mathrm{H}_{2} \mathrm{O}+\mathrm{Na}^{+}+\mathrm{Cl}^{-}$and $\mathrm{CO}_{2}+\mathrm{H}_{2} \mathrm{O}+\mathrm{Na}^{+}+\mathrm{Cl}^{-}$ systems.

\begin{tabular}{|c|c|c|}
\hline System & $\boldsymbol{P}_{\text {sat }}(\mathbf{A A D}$ \%) & $\boldsymbol{V}_{\boldsymbol{m}}(\mathbf{A A D}$ \%) \\
\hline $\mathrm{CH}_{4}+\left(\mathrm{H}_{2} \mathrm{O}+\mathrm{Na}^{+}+\mathrm{Cl}^{-}\right)$ & 33 & 33 \\
\hline $\mathrm{CO}_{2}+\left(\mathrm{H}_{2} \mathrm{O}+\mathrm{Na}^{+}+\mathrm{Cl}\right)$ & 32 & 28 \\
\hline
\end{tabular}

\section{Conclusions}

An electrolyte version of the Cubic Plus Association (eCPA) equation of state has been adapted to systems containing $\mathrm{CH}_{4}, \mathrm{CO}_{2}, \mathrm{H}_{2} \mathrm{O}$ and $\mathrm{NaCl}$ (up to 5 molal) at temperatures and pressures up to $773 \mathrm{~K}$ and $200 \mathrm{MPa}$. Its purpose is to represent the phase behavior (including salting-out effect and critical points) and the densities of phases in a range of temperature and pressure encountered in deep reservoir and basins. The goal of the parameterization proposed is not to reach very high accuracy for phase equilibrium and volumetric properties, but rather to develop a semi-predictive approach to model this system while allowing an easy extension to other compounds. 
Among the parameters of the pure molecular species only the cross associating volume of $\mathrm{CO}_{2}$ has been modified from the literature values, to better represent the high temperatures phase equilibrium of the $\mathrm{CO}_{2}+\mathrm{H}_{2} \mathrm{O}$ binary system. Parameters of the pure ions $\left(\mathrm{Na}^{+}\right.$and $\left.\mathrm{Cl}^{-}\right)$have been adjusted to represent vapor pressures and mean ionic activity coefficients of brine. Finally, binary interaction parameters between each gas $\left(\mathrm{CO}_{2}\right.$ and $\left.\mathrm{CH}_{4}\right)$ with $\mathrm{H}_{2} \mathrm{O}$ and ions have been fitted to represent phase equilibrium with a special focus on critical phase envelope closure and salting out effects.

Without salt, predictions for pure component saturation vapor pressures and liquid molar volumes present an average absolute deviation (AAD) lower than $3 \%$ compared to experimental reference values. The pure component molar volumes out of saturation show an AAD lower than $4 \%$. The highest deviations in densities are observed in the vicinity of the critical coordinates of pure water and this effect increases when gases or salts are added to the system. For each binary system, $\mathrm{CH}_{4}+$ $\mathrm{CO}_{2}, \mathrm{CH}_{4}+\mathrm{H}_{2} \mathrm{O}$ and $\mathrm{CO}_{2}+\mathrm{H}_{2} \mathrm{O}$, binary interaction parameters have been fitted to correctly predict the shape of the fluid phase envelopes (including liquid-vapor critical points) in the entire temperature and pressure range considered $(219 \mathrm{~K}$ to $633 \mathrm{~K}$ and up to $250 \mathrm{MPa})$. The methane concentration in both phases of the $\mathrm{CH}_{4}+\mathrm{CO}_{2}$ binary system is represented with an AAD lower than $9 \%$. The methane solubility in water is represented within $16 \%$ and $8 \%$ for the methane content of the vapor. The $\mathrm{CO}_{2}$ solubility in water is within $26 \%$, while the $\mathrm{CO}_{2}$ in the vapor phase shows an average deviation of $12 \%$. All molar volumes are represented with an AAD lower than $3 \%$. The few VLE data which were found for the $\mathrm{CH}_{4}+\mathrm{CO}_{2}+\mathrm{H}_{2} \mathrm{O}$ ternary system are fairly well predicted with the model without extra parameter and comfort the ability of the eCPA equation of state to be extended to multi-component systems. In the presence of salts, gas + ion binary interaction parameter have been fitted, and all phase equilibrium are qualitatively correctly described, and more specifically the salting out effect. The solubility of methane or $\mathrm{CO}_{2}$ in brines, up to 5 molal, is represented with an AAD of $33 \%$ in a large temperature and pressure range (up to $673 \mathrm{~K}$ and $150 \mathrm{MPa}$ ). It should be noticed that for high temperatures, experimental data are relatively scarce and not always consistent. No data exist for water content of the vapor phase in these conditions.

The new eCPA model can be easily extended to other components including also others ions to better represent real fluid behavior in very deep reservoir conditions.

\section{Acknowledgements}

Authors gratefully acknowledge TOTAL for financial support of this work and E. Brosse and X. Guichet (IFP Energies nouvelles) for fruitful discussions.

\section{List of symbols}

AAD attractive term in SRK EoS $\left(\mathrm{Pa}^{\mathrm{m}} \mathrm{m}^{6} \cdot \mathrm{mol}^{-2}\right)$

Average Absolute Deviation (\%) 
b

DIPPR

D

$D_{0}$

e

eCPA

F

$\mathrm{g}(\rho)$

$\mathrm{k}_{\mathrm{ij}}$

$\mathrm{m}$

MSA

$\mathrm{n}$

$\mathrm{N}$

$\mathrm{N}_{\mathrm{av}}$

$\mathrm{R}$

SRK

$\mathrm{T}$

$v$

$V$

VLE

$\mathrm{x}_{\mathrm{i}}$

$X^{A_{i}}$

$\mathrm{y}_{\mathrm{i}}$

$Z_{i}$

$\alpha$

$\beta^{A_{i} B_{j}}$

$\Delta^{A_{i} B_{j}}$

$\varepsilon^{A_{i} B_{j}}$

$\pi$

$\rho$ co-volume term in SRK EoS $\left(\mathrm{m}^{3} \cdot \mathrm{mol}^{-1}\right)$

Design Institute of Physical Property Data

solution dielectric constant

vacuum permittivity $\left(\mathrm{F} \cdot \mathrm{m}^{-1}\right)$

elementary charge (C)

electrolyte Cubic Plus Association

dummy variable used to present $\mathrm{AAD}$ equation

radial distribution function

binary interaction parameter

parameter used in the alpha function

Mean Spherical Approach

number of mole

number of data

Avogadro's constant

ideal gas constant (J.(mol.K) $\left.)^{-1}\right)$

Soave Redlich Kwong

absolute temperature (Kelvin)

molar volume $\left(\mathrm{m}^{3} \cdot \mathrm{mol}^{-1}\right)$

volume $\left(\mathrm{m}^{3}\right)$

Vapor Liquid Equilibrium

molar fraction of component $i$ in liquid phase

Unbonded fraction of site A of the molecule $i$

molar fraction of component $i$ in vapor phase

valence of ion $i$

Greek letters :

tunable parameter used in Simonin's model

association volume between site A on molecule $i$ and site B on molecule $j\left(\AA^{3}\right)$

association strength between site $\mathrm{A}$ on molecule $i$ and site $\mathrm{B}$ on molecule $j$ $\left(\AA^{3}\right)$

association energy of interaction between site A on molecule $i$ and site B on molecule $j$, per molecule (J)

pi number

molar density of solution $\left(\mathrm{mol} . \mathrm{m}^{-3}\right)$ 


\section{Subscripts:}

0

$\mathrm{A}_{\mathrm{i}}$

c

$i$

j

$\mathrm{m}$

s

$0,1,2$

$+$

assoc

hs

res standard property

site A of the molecule $i$

critical

applied to component $i$

applied to component $j$

molar

solvent

Superscripts:

reduced property

iterative values to differ parameters for $k_{i j}$ evolution with temperature

positive charge

negative charge

association

hard sphere

residual 


\section{References}

Reference List

1. Addicks J., Owren G. A., Fredheim A. O. and Tangvik K. (2002) Solubility of carbon dioxide and methane in aqueous methyldiethanolamine solutions. J. Chem. Eng. Data 47, 855-860.

2. Ai N., Chen J. and Fei W. (2005) Solubility of Carbon Dioxide in Four Mixed Solvents. $J$. Chem. Eng. Data 50, 492-496.

3. Akerloef G. (1930) Activity coefficients of sodium, potassium and lithium chlorides and hydrochloric acid at infinite dilution in water-methyl alcohol mixtures. J. Am. Chem. Soc. 52, 2353-2368.

4. Amado G. E. and Blanco L. H. (2004) Osmotic and Activity Coefficients of Aqueous Solutions of $\mathrm{KCl}$ at Temperatures of 283.15, 288.15, 293.15 and $298.15 \mathrm{~K}$. A New Isopiestic Apparatus. Fluid Phase Equilib. 226, 261-265.

5. Anderson G. K. (2002) Solubility of Carbon Dioxide in Water under Incipient Clathrate Formation Conditions. J. Chem. Eng. Data 47, 219-222.

6. Apelblat A. and Korin E. (1998) The vapour pressures of saturated aqueous solutions of sodium chloride, sodium bromide, sodium nitrate, sodium nitrite, potassium iodate, and rubidium chloride at temperatures from $227 \mathrm{~K}$ to $323 \mathrm{~K}$. J. Chem. Thermodyn. 30, 59-71.

7. Apelblat A. and Manzurola E. (1999) Volumetric properties of water, and solutions of sodium chloride and potassium chloride at temperatures from $\mathrm{T}=277.15 \mathrm{~K}$ to $\mathrm{T}=343.15 \mathrm{~K}$ at molalities of $(0.1,0.5$, and 1.0)mol. J. Chem. Thermodyn. 31, 869-893.

8. Baabor S. J., Gilchrist B. M. A. and Delgado R. E. (1994) Isopiestic study of saline systems. IV. LiCl-NaCl-H2O system at 25 C. Bol. Soc. Chil. Quim. 39, 95-101.

9. Ball F. X., Fürst W. and Renon H. (1985) Representation of deviation from ideality in concentrated aqueous solutions of electrolytes using a mean spherical appoximation molecular model. AIChE J. 31, 392.

10. Bamberger A., Sieder G. and Maurer G. (2000) High-pressure (vapor+liquid) equilibrium in binary mixtures of (carbon dioxide+water or acetic acid) at temperatures from 313 to $353 \mathrm{~K} . J$. Supercrit. Fluids 17, 97-110.

11. Bando S., Takemura F., Nishio M., Hihara E. and Akai M. (2003) Solubility of CO2 in Aqueous Solutions of $\mathrm{NaCl}$ at (30 to 60) ${ }^{\circ} \mathrm{C}$ and (10 to 20) MPa. J. Chem. Eng. Data 48, 576579 .

12. berling D., Joensson B. and Olofsson G. (1999) The Use of Isothermal Heat-Conduction Calorimetry in Direct Measurements of Solvent Vapor Pressure. J. Sol. Chem. 28, 693-710.

13. Bermejo M. D., Martin A., Florusse L. J., Peters C. J. and Cocero M. J. (2005) The influence of $\mathrm{Na} 2 \mathrm{SO} 4$ on the $\mathrm{CO} 2$ solubility in water at high pressure. Fluid Phase Equilib. 238, 220 228.

14. Bischoff J. L. and Rosenbauer R. J. (1988) Liquid-vapor relations in the critical region of the system $\mathrm{NaCl}-\mathrm{H}_{2} \mathrm{O}$ from 380 to $415^{\circ} \mathrm{C}$ : A refined determination of the critical point and twophase boundary of seawater. Geochim. Cosmochim. Acta 2121-2126. 
15. Blanco L. H., Eliseo Amado G. and Calvo J. C. (2008) Osmotic and activity coefficients of dilute aqueous solutions of the series Me4NI to MeBu3NI at 298.15 K. Fluid Phase Equilib. 268, 90-94.

16. Blount C. W. (1980) Methane Solubility in Aqueous $\mathrm{NaCl}$ Solutions at Elevated Temperatures and Pressures . Proceedings / Fourth United States Gulf Coast Geopressured-Geothermal Energy Conference, Research and Development 4, 1225-1262.

17. Blum L. (1975) Mean spherical model for asymmetric electrolytes : I. Method of solution. Mol. Phys. 30, 1529-1535.

18. Blum L. (1977) Mean spherical model for asymmetric electrolytes. 2. Thermodynamic properties and the pair correlation function. J. Phys. Chem. 81, 1311-1317.

19. Born M. (1920) Volumen und Hydratationswärme der Ionen. Z. Phys. 1, 45-49.

20. Boyd G. E. (1977) Ionic interactions in aqueous electrolyte-polyelectrolyte mixtures: Comparisons with mixtures of sodium chloride and the model electrolyte benzyltrimethylammonium chloride at $25^{\circ} \mathrm{C} . J$. Sol. Chem. 6, 135-148.

21. Briones J. A., Mullins J. C., Thies M. C. and Kim B. U. (1987) Ternary phase equilibria for acetic acid-water mixtures with supercritical carbon dioxide. Fluid Phase Equilib. 36, 235246.

22. Brown A. S. and MacInnes D. A. (1935) The Determination of Activity Coefficients from the Potentials of Concentration Cells with Transference. I. Sodium Chloride at $25^{\circ} . \mathrm{J} . \mathrm{Am}$. Chem. Soc. 57, 1356-1362.

23. Burge D. E. (1963) Osmotic coefficients in aqueous solutions. Studies with the vapor pressure osmometer. J. Phys. Chem. 67, 2590-2593.

24. Carroll J. J. (1998) The solubility of methane in aqueous solutions of monoethanolamine, diethanolamine and triethanolamine. Can. J. Chem. Eng. 76, 945-951.

25. Chapoy A., Coquelet C. and Richon D. (2003) Solubility measurement and modeling of water in the gas phase of the methane/water binary system at temperatures from 283.08 to $318.12 \mathrm{~K}$ and pressures up to $34.5 \mathrm{MPa}$. Fluid Phase Equilib. 214, 101-117.

26. Chapoy A., Mohammadi A. H., Chareton A., Tohidi B. and Richon D. (2004a) Measurement and modeling of gas solubility and literature review of the properties for the carbon dioxidewater system. Ind. Eng. Chem. Res. 43, 1794-1802.

27. Chapoy A., Mohammadi A. H., Richon D. and Tohidi B. (2004b) Gas solubility measurement and modeling for methane-water and methane-ethane-n-butane-water systems at low temperature conditions. Fluid Phase Equilib. 220, 113-121.

28. Cramer S. D. (1982) The Solubility of Methane, Carbon Dioxide, and Oxygen in Brines from 0 Degrees to $300^{\circ} \mathrm{C}$. Bur. Mines Rep. Invest. RI 8706, 1-17.

29. Crovetto R. and Wood R. H. (1992) Solubility of $\mathrm{Co} 2$ in water and density of aqueous $\mathrm{Co} 2$ near the solvent critical temperature. Fluid Phase Equilib. 74, 271-288.

30. Crovetto R. and Wood R. H. (1991) New detection method for determining phase boundaries. Fluid Phase Equilib. 65, 253-261. 
31. Culberson O. L. (1951) Phase equilibria in hydrocarbon-water systems: III The solubility of methane in water at pressures to 10000 psia. Pet Trans. AIME 192, 223-226.

32. Culberson O. L. and McKetta J. J. (1950) Phase Equilibria in Hydrocarbon - Water Systems. II - The Solubility of Ethane in Water at Pressures to 10,000 psi. Trans. Am. Inst. Min. Metall. Pet. Eng. 189, 319-322.

33. D'souza R., Patrick J. R. and Teja A. S. (1988) High pressure phase equilibria in the carbon dioxide - n-Hexadecane and carbon dioxide - water systems. Can. J. Chem. Eng. 66, 319-323.

34. Dalmolin I., Skovroinski E., Biasi A., Corazza M. L., Dariva C. and Oliveira J. V. (2006) Solubility of carbon dioxide in binary and ternary mixtures with ethanol and water. Fluid Phase Equilib. 245, 193-200.

35. Davis J. E. and McKetta J. J. (1960) Solubility of Methane in Water. Pet. Refiner 39, 205-206.

36. de Hemptinne J. C., Mougin P., Barreau A., Ruffine L., Tamouza S. and Inchekel R. (2006) Application to petroleum engineering of statistical thermodynamics - Based equations of state. Oil \& Gas Sci. Tech. - Rev. IFP Energies nouvelles 61, 363-386.

37. Dell'Era C., Uusi-Kyyny P., Pokki J. P., Pakkanen M. and Alopaeus V. (2010) Solubility of carbon dioxide in aqueous solutions of diisopropanolamine and methyldiethanolamine. Fluid Phase Equilib. 293, 101-109.

38. Derawi S. O. (2002) Modelling of Phase Equilibria containing Associating Fluids. Ph. D. thesis, Technical University of Denmark.

39. Dhima A. (1998) Solubilité des gaz naturels dans l'eau à pression élevée. Ph. D. thesis, Université Claude Bernard - Lyon 1.

40. Dhima A., de Hemptinne J. C. and Jose J. (1999) Solubility of Hydrocarbons and CO2 Mixtures in Water under High Pressure. Ind. Eng. Chem. Res. 38, 3144-3161.

41. Dohrn R., Bünz A. P., Devlieghere F. and Thelen D. (1993) Experimental measurements of phase equilibria for ternary and quaternary systems of glucose, water, $\mathrm{CO} 2$ and ethanol with a novel apparatus. Fluid Phase Equilib. 83, 149-158.

42. Downes C. J. (1970) Activity coefficients of sodium chloride in the system sodium chloridesodium perchlorate-water at 25.deg., and the use of amalgam electrodes. J. Chem. Eng. Data $15,444-446$.

43. Downes C. J. (1973) Osmotic and activity coefficients for system sodium chloridemanganese(II) chloride-water at 25.deg. J. Chem. Eng. Data 18, 412-416.

44. Downes C. and Pitzer K. (1976) Thermodynamics of electrolytes. Binary mixtures formed from aqueous $\mathrm{NaCl}, \mathrm{Na} 2 \mathrm{SO} 4, \mathrm{CuCl} 2$, and $\mathrm{CuSO} 4$, at $25^{\circ} \mathrm{C}$. J. Sol. Chem. 5, 389-398.

45. Duan Z., Moller N. and Weare J. H. (1992a) An equation of state for the $\mathrm{CH}_{4}-\mathrm{CO}_{2}-\mathrm{H}_{2} \mathrm{O}$ system: II. Mixtures from 50 to $1000^{\circ} \mathrm{C}$ and 0 to 1000 bar. Geochim. Cosmochim. Acta 56, 2619-2631.

46. Duan Z., Moller N. and Weare J. H. (1996) A general equation of state for supercritical fluid mixtures and molecular dynamics simulations of mixture PVTx properties. Geochim. Cosmochim. Acta 60, 1209-1216. 
47. Duan Z., Moller N. and Weare J. H. (2003) Equations of State for the $\mathrm{NaCl}-\mathrm{H}_{2} \mathrm{O}-\mathrm{CH}_{4}$ System and the $\mathrm{NaCl}-\mathrm{H}_{2} \mathrm{O}-\mathrm{CO}_{2}-\mathrm{CH}_{4}$ System: Phase Equilibria and Volumetric Properties above 573 K. Geochim. Cosmochim. Acta 67, 671-680.

48. Duan Z. H. and Mao S. D. (2006) A thermodynamic model for calculating methane solubility, density and gas phase composition of methane-bearing aqueous fluids from 273 to $523 \mathrm{~K}$ and from 1 to 2000 bar. Geochim. Cosmochim. Acta 70, 3369-3386.

49. Duan Z. H., Moller N., Greenberg J. and Weare J. H. (1992b) The Prediction of Methane Solubility in Natural-Waters to High Ionic-Strength from O-Degrees-C to 250-Degrees-C and from 0 to 1600 Bar. Geochim. Cosmochim. Acta 56, 1451-1460.

50. Duan Z. H. and Sun R. (2003) An improved model calculating CO2 solubility in pure water and aqueous $\mathrm{NaCl}$ solutions from 273 to $533 \mathrm{~K}$ and from 0 to 2000 bar. Chem. Geol. 193, 257271.

51. Duan Z. H., Sun R., Zhu C. and Chou I. M. (2006) An improved model for the calculation of $\mathrm{CO} 2$ solubility in aqueous solutions containing $\mathrm{Na}+, \mathrm{K}+, \mathrm{Ca} 2+, \mathrm{Mg} 2+, \mathrm{Cl}-$, and $\mathrm{SO} 42-. \mathrm{Mar}$. Chem. 98, 131-139.

52. Duffy J. R., Smith N. O. and Nagy B. (1961) Solubility of natural gases in aqueous salt solutions: Liquidus surfaces in the system $\mathrm{CH} 4-\mathrm{H} 2 \mathrm{O}-\mathrm{NaCl} 2-\mathrm{CaCl} 2$ at room temperatures and at pressures below 1000 psia. Geochim. Cosmochim. Acta 24, 23-31.

53. Elis A. J. and Golding R. M. (1963) The solubility of carbon dioxide above $100 \mathrm{C}$ in water and in sodium chloride solutions. Am. J. Sci. 261, 47-60.

54. Ellis A. J. (1966) Partial molal volumes of alkali chlorides in aqueous solution to 200[degree]. J. Chem. Soc. A 1579-1584.

55. Esteso M. A., Fernandez-Merida L., Hernandez-Luis F. F. and Gonzales-Diaz O. M. (1989) Activity Coefficients in the System $\mathrm{NaCl}+\mathrm{Na}_{2}$ Succinate $+\mathrm{H}_{2} \mathrm{O}$ at $25^{\circ} \mathrm{C}$. Ber. Bunsen-Ges. Phys. Chem. 93, 213-217.

56. Fabuss B. M., Korosi A. and Hug A. K. M. S. (1966) Densities of Binary and Ternary Aqueous Solutions of $\mathrm{NaCl}, \mathrm{Na} 2 \mathrm{SO} 4$ and $\mathrm{MgSO} 4$ of Sea Waters, and Sea Water Concentrates. J. Chem. Eng. Data 11, 325-331.

57. Fenghour A., Wakeham W. A. and Watson J. T. R. (1996) Densities of (water + carbon dioxide) in the temperature range $415 \mathrm{~K}$ to $700 \mathrm{~K}$ and pressures up to $35 \mathrm{MPa}$. J. Chem. Thermodyn. 28, 433-446.

58. Ferrentino G., Barletta D., Balaban M. O., Ferrari G. and Poletto M. (2010) Measurement and prediction of $\mathrm{CO} 2$ solubility in sodium phosphate monobasic solutions for food treatment with high pressure carbon dioxide. J. Supercrit. Fluids 52, 142-150.

59. Filippov V. K., Charykov N. A. and Fedorov Y. A. (1986) The $\mathrm{NaCl}-\mathrm{NiCl}_{2}-\mathrm{H}_{2} \mathrm{O}$ and $\mathrm{NaCl}-$ $\mathrm{CuCl}_{2}-\mathrm{H}_{2} \mathrm{O}$ Systems at $25^{\circ} \mathrm{C}$. Russ. J. Inorg. Chem. 31, 1071-1074.

60. Filiz M. and Gülen J. (2008) Investigation of the aqueous salt solutions of some first and second group metals at various pressures. Fluid Phase Equilib. 267, 18-22.

61. Folas G. K., Berg O. J., Solbraa E., Fredheim A. O., Kontogeorgis G. M., Michelsen M. L. and Stenby E. H. (2007) High-pressure vapor-liquid equilibria of systems containing ethylene glycol, water and methane - Experimental measurements and modeling. Fluid Phase Equilib. 251, 52-58. 
62. Fonseca I. M. A., Almeida J. P. B. and Fachada H. C. (2007) Automated apparatus for gas solubility measurements. J. Chem. Thermodyn. 39, 1407-1411.

63. Galobardes J. F., van Hare D. F. and Rogers L. B. (1981) Solubility of Sodium Chloride in Dry Steam. J. Chem. Eng. Data 26, 363-366.

64. Gardner E. R., Jones P. J. and De Nordwall H. J. (1963) Osmotic coefficients of some aqueous sodium chloride solutions at high temperature. T. Faraday Soc. 59, 1994-2000.

65. Gehrig M., Lentz H. and Franck E. U. (1983) Concentrated Aqueous Sodium Chloride Solutions from 200 to $600 \mathrm{C}$ and to 3000 Bar. Phase Equilibria and pvT-data. Ber. BunsenGes. Phys. Chem. 87, 597-600.

66. Gibbard H. F. Jr., Scatchard G., Rousseau R. A. and Creek J. L. (1974) Liquid-Vapor Equilibrium of Aqueous Sodium Chloride, from 298 to $373 \mathrm{~K}$ and from 1 to $6 \mathrm{~mol} \mathrm{kg-1}$, and Related Properties. J. Chem. Eng. Data 19, 281-288.

67. Gillespie, P. C. and Wilson, G. M. (1982) Vapor-liquid and Liquid-liquid equilibria: Watermethane; water-carbon dioxide; water-hydrogen sulfide; water-n-pentane; water-methane-npentane. Research Report 48. GPA. Provo, UT.

68. Glazkova E. N., Izmailova G. A., Lebed B. I. and Rubtsov V. I. (1997) Activity coefficients of sodium chloride in the systems $\mathrm{NaCl}-\mathrm{CaCl}_{2}-\mathrm{H}_{2} \mathrm{O}$ and $\mathrm{NaCl}-\mathrm{MgCl}_{2}-\mathrm{H}_{2} \mathrm{O}$ at the temperatures 278.15 -303.15 K. Zh. Neorg. Khim. 42, 1580-1583.

69. Gorbatchev S. V., Kondratev V. P., Androsonov V. I. and Kolupaev V. G. (1974) Specific Volumes of Aqueous Solutions of Alkali-Metal Chlorides. Russ. J. Phys. Chem. 48, 16411642 .

70. Grant-Taylor D. F. (1981) Partial molar volumes of sodium chloride solutions at 200 bar, and temperatures from 175 to $350^{\circ} \mathrm{C}$. J. Sol. Chem. 10,621-630.

71. Gu F. (1998) Solubility of Carbon Dioxide in Aqueous Sodium Chloride Solution under High Pressure. Gaoxiao Huaxue Gongcheng Xuebao 12, 118-123.

72. Guendouzi M. E., Dinane A. and Mounir A. (2001) Water activities, osmotic and activity coefficients in aqueous chloride solutions at $\mathrm{T}=298.15 \mathrm{~K}$ by the hygrometric method. $J$. Chem. Thermodyn. 33, 1059-1072.

73. Gui X., Tang Z. and Fei W. (2010) CO2 Capture with Physical Solvent Dimethyl Carbonate at High Pressures. J. Chem. Eng. Data 55, 3736-3741.

74. Hakuta T., Goto T. and Ishizaka S. (1975) Boiling Point Elevation of Aqueous Solution Containing Inorganic Salt. Nippon Kaisui Gakkaishi 28, 151-155.

75. Hamer W. J. and Wu Y. C. (1972) Osmotic Coefficients and Mean Activity Coefficients of Uni-Univalent Electrolytes in Water at 25 C. J. Phys. Chem. Ref. Data 1, 1047-1099.

76. Harned H. S. and Cook M. A. (1939) The Thermodynamics of Aqueous Sodium Chloride Solutions from 0 to $40-1$ from Electromotive Force Measurements. J. Am. Chem. Soc. 61, 495497.

77. He S. L. and Morse J. W. (1993) The Carbonic-Acid System and Calcite Solubility in Aqueous Na-K-Ca-Mg-Cl-So4 Solutions from 0 to 90 -Degrees-C. Geochim. Cosmochim. Acta 57, 3533-3554. 
78. Hernandez-Hernandez F., Perez-Villasenor F., Hernandez-Ruiz V. and Iglesias-Silva G. A. (2007) Activity Coefficients of $\mathrm{NaCl}$ in $\mathrm{H} 2 \mathrm{O}+\mathrm{MeOH}+\mathrm{EtOH}$ by Electromotive Force at 298.15 K. J. Chem. Eng. Data 52, 959-964.

79. Hernandez-Luis F., Fernandez-Merida L., Galleguillos H., Esteso M. A., Ooi K. S., Khoo S. K. and Lim T. K. (1995) Activity coefficients in quaternary electrolytic systems: $\mathrm{NaCl}+$ $\mathrm{NaFormate}+\mathrm{NaAcetate}+\mathrm{H} 2 \mathrm{O}, \mathrm{NaCl}+\mathrm{NaFormate}+\mathrm{NaPropionate}+\mathrm{H} 2 \mathrm{O}$ and $\mathrm{NaBr}+$ NaFormate + NaAcetate + H2O. Fluid Phase Equilib. 109, 139-156.

80. Hernandez-Luis F., Galleguillos H. R., Fernandez-Merida L. and Gonzalez-Diaz O. (2009) Activity coefficients of $\mathrm{NaCl}$ in aqueous mixtures with increasing co-solvent: Formamide+water mixtures at 298.15 K. Fluid Phase Equilib. 275, 116-126.

81. Hernandez-Luis F., Grandoso D. and Lemus M. (2004) Activity Coefficients of $\mathrm{NaCl}$ in Fructose + Water at 298.15 K. J. Chem. Eng. Data 49, 668-674.

82. Hernandez-Luis F., Rodriguez-Raposo R., Galleguillos H. R. and Morales J. W. (2010) Activity Coefficients of $\mathrm{NaCl}$ in Aqueous Mixtures with High Relative Permittivity Cosolvent: Ethylene Carbonate + Water at 298.15 K. J. Chem. Eng. Data 55, 3349-3355.

83. Hilbert R. (1979) pvT-data of water and aqueous sodium chloride solutions up to $873 \mathrm{~K}, 4000$ bar and 25 weight percent $\mathrm{NaCl}$. Ph. D. thesis, Karlsruhe.

84. Hu J., Duan Z., Zhu C. and Chou I. M. (2007) PVTx properties of the $\mathrm{CO}_{2}-\mathrm{H}_{2} \mathrm{O}$ and $\mathrm{CO}_{2}-$ $\mathrm{H}_{2} \mathrm{O}-\mathrm{NaCl}$ systems below $647 \mathrm{~K}$ : Assessment of experimental data and thermodynamic models. Chem. Geol. 238, 249-267.

85. Huang S. H. and Radosz M. (1990) Equation of state for small, large, polydisperse and associating molecules. Ind. Eng. Chem. Res. 29, 2284-2294.

86. Hubert N., Gabes Y., Bourdet J. B. and Schuffenecker L. (1995) Vapor Pressure Measurements with a Nonisothermal Static Method between 293.15 and $363.15 \mathrm{~K}$ for Electrolyte Solutions. Application to the $\mathrm{H} 2 \mathrm{O}+\mathrm{NaCl}$ System. J. Chem. Eng. Data 40, 891894.

87. Inchekel R., de Hemptinne J. C. and Fürst W. (2008) The simultaneous representation of dielectric constant, volume and activity coefficients using an electrolyte equation of state. Fluid Phase Equilib. 271, 19-27.

88. Iwai Y., Uno M., Nagano H. and Arai Y. (2004) Measurement of solubilities of palmitic acid in supercritical carbon dioxide and entrainer effect of water by FTIR spectroscopy. $J$. Supercrit. Fluids 28, 193-200.

89. Jablczynski K. (1922) The vapor tension and the law of equilibrium of electrolytes. Rocz. Chem. 2, 467-473.

90. Jablczynski K. and Kon S. (1923) Ebullioscopic studies. Rocz. Chem. 3, 206-227.

91. Jackson K., Bowman L. E. and Fulton J. L. (1995) Water Solubility Measurements In Supercritical Fluids and High-Pressure Liquids Using Near-Infrared Spectroscopy. Anal. Chem. 67, 2368-2372.

92. Janz G. J. and Gordon A. R. (1943) The Thermodynamics of Aqueous Solutions of Sodium Chloride at Temperatures from $15-45^{\circ}$ from e. m. f. Measurements on Cells with Transference. J. Am. Chem. Soc. 65, 218-221. 
93. Jarne C., Blanco S. T., Artal M., Rauzy E., Otin S. and Velasco I. (2004) Dew points of binary carbon dioxide + water and ternary carbon dioxide + water + methanol mixtures:

Measurement and modelling. Fluid Phase Equilib. 216, 85-93.

94. Ji X., Lu X., Li S., Zhang L., Wang Y. and Shi J. (2001) Determination of the Activity Coefficients of $\mathrm{NaCl}$ in the System NaCl-NH4Cl-H2O. J. Sol. Chem. 30, 463-473.

95. Ji X., Tan S. P., Adidharma H. and Radosz M. (2005) SAFT1-RPM Approximation Extended to Phase Equilibria and Densities of $\mathrm{CO} 2-\mathrm{H} 2 \mathrm{O}$ and $\mathrm{CO} 2-\mathrm{H} 2 \mathrm{O}-\mathrm{NaCl}$ Systems. Ind. Eng. Chem. Res. 44, 8419-8427.

96. Johnston S. M. (1907) XXXII. - The Boiling and Freezing Points of Concentrated Aqueous Solutions, and the Question of the Hydration of the Solute. Trans. R. Soc. Edinburgh 45, 855884.

97. Kahlenberg L. (1900) The Theory of Electrolytic Dissociation as Viewed in the Light of Facts Recently Ascertained. J. Phys. Chem. 5, 339-392.

98. Khaibullin I. K. and Borisov N. M. (1966) Experimental Investigation of the Thermal Properties of Aqueous and Vapor Solutions of Sodium and Potassium Chlorides at Phase Equilibrium. High Temperature 4, 489-494.

99. Khoshkbarchi M. K. and Vera J. H. (1996) Measurement and modeling of activities of amino acids in aqueous salt systems. AIChE J. 42, 2354-2364.

100. Kiepe J. (2002) Experimental Determination and Prediction of Gas Solubility Data for CO2 + $\mathrm{H} 2 \mathrm{O}$ Mixtures Containing $\mathrm{NaCl}$ or $\mathrm{KCl}$ at Temperatures between 313 and $393 \mathrm{~K}$ and Pressures up to $10 \mathrm{MPa}$. Ind Eng Chem Res 41, 4393-4398.

101. Kiepe J., de Araujo Rodrigues A. K., Horstmann S. and Gmehling J. (2003a) Experimental Determination and Correlation of Liquid Density Data of Electrolyte Mixtures Containing Water or Methanol. Ind. Eng. Chem. Res. 42, 2022-2029.

102. Kiepe J., Horstmann S., Fischer K. and Gmehling J. (2003b) Experimental Determination and Prediction of Gas Solubility Data for Methane + Water Solutions Containing Different Monovalent Electrolytes. Ind. Eng. Chem. Res. 42, 5392-5398.

103. Kim Y. S., Ryu S. K., Yang S. O. and Lee C. S. (2003) Liquid Water-Hydrate Equilibrium Measurements and Unified Predictions of Hydrate-Containing Phase Equilibria for Methane, Ethane, Propane, and Their Mixtures. Ind. Eng. Chem. Res. 42, 2409-2414.

104. King M. B., Mubarak A., Kim J. D. and Bott T. R. (1992) The mutual solubilities of water with supercritical and liquid carbon dioxides. J. Supercrit. Fluids 5, 296-302.

105. Koennecke T., Neck V., Fanghaenel T. and Kim J. I. (1997) Activity coefficients and pitzer parameters in the systems $\mathrm{Na}+/ \mathrm{Cs}+/ \mathrm{Cl}-/ \mathrm{TcO} 4-$ or $\mathrm{ClO} 4-/ \mathrm{H} 2 \mathrm{O}$ at $25^{\circ} \mathrm{C}$. J. Sol. Chem. 26, 561577.

106. Kontogeorgis G. M., Folas G. K., Muro-Sune N., Leon F. R. and Michelsen M. L. (2008) Solvation phenomena in association theories with applications to oil \& gas and chemical industries. Oil \& Gas Sci. Tech. - Rev. IFP Energies nouvelles 63, 305-319.

107. Kontogeorgis G. M., Voutsas E. C., Yakoumis I. V. and Tassios D. P. (1996) An equation of state for associating fluids. Ind. Eng. Chem. Res. 35, 4310-4318. 
108. Kontogeorgis M. (2006) Ten Years with the CPA (Cubic-Plus-Association) Equation of State. Part 2. Cross-Associating and Multicomponent Systems. Ind Eng Chem Res 45, 4869-4878.

109. Korosi A. and Fabuss B. M. (1968) Viscosities of binary aqueous solutions of sodium chloride, potassium chloride, sodium sulfate, and magnesium sulfate at concentrations and temperatures of interest in desalination processes. J. Chem. Eng. Data 13, 548-552.

110. Koschel D., Coxam J. Y., Rodier L. and Majer V. (2006) Enthalpy and solubility data of CO2 in water and $\mathrm{NaCl}(\mathrm{aq})$ at conditions of interest for geological sequestration. Fluid Phase Equilib. 247, 107-120.

111. Kovyrzina V. P., Sidorova E. E., Zakharova T. N. and Berg L. G. (1966) Thermographic Determination of Thermodynamic Activity of Salt Solutions. Zh. Fiz. Khim. 40, 1489-1493.

112. Kuramochi H., Noritomi H., Hoshino D. and Nagahama K. (1997) Measurements of Vapor Pressures of Aqueous Amino Acid Solutions and Determination of Activity Coefficients of Amino Acids. J. Chem. Eng. Data 42, 470-474.

113. Lanier R. D. (1965) Activity Coefficients of Sodium Chloride in Aqueous Three-Component Solutions by Cation-Sensitive Glass Electrodesla. J. Phys. Chem. 69, 3992-3998.

114. Lannung A. (1934) Measurement of the Vapor Pressure of Aqueous Solutions of the Alkali Halogenides. Z. Phys. Chem. Abt. A 170, 134-144.

115. Lebed V. I. and Aleksandrov V. V. (1964) Electromotive Forces and Normal Potentials of Cells without Transport at Various Temperatures. Russ. J. Phys. Chem. 38, 1414-1417.

116. Legrand (1836) Bestimmung der Variationen der Loslichkeit mehrerer Salze, und ++ber ihren Einfluss auf den Siedpunct der Auflosung. Ann. Pharm. 17, 29-37.

117. Lekvam K. and Bishnoi P. R. (1997) Dissolution of methane in water at low temperatures and intermediate pressures. Fluid Phase Equilib. 131, 297-309.

118. Lemmon, E. (2006) NIST Reference Fluid Thermodynamic and Transport Properties Database (REFPROP). Version 7.0.

119. Leopold H. G. and Johnston J. (1927) The vapor pressure of the saturated aqueous solutions of certain salts. J. Am. Chem. Soc. 49, 1974-1988.

120. Li Y. H. and Tsui T. F. (1971) The solubility of CO2 in water and sea water. J. Geophys. Res. 76, 4203-4207.

121. Li Z., Dong M., Li S. and Dai L. (2004) Densities and Solubilities for Binary Systems of Carbon Dioxide + Water and Carbon Dioxide + Brine at $59^{\circ} \mathrm{C}$ and Pressures to $29 \mathrm{MPa} . J$. Chem. Eng. Data 49, 1026-1031.

122. Liu C. t. and Lindsay W. T., Jr. (1972) Thermodynamics of sodium chloride solutions at high temperatures. J. Sol. Chem. 1, 45-69.

123. Malegaonkar M. B., Dholabhai P. D. and Bishnoi P. R. (1997) Kinetics of carbon dioxide and methane hydrate formation. Can. J. Chem. Eng. 75, 1090-1099.

124. Malinin S. D. and Kurovskaya N. A. (1975) Solubility of $\mathrm{CO}_{2}$ in Chloride Solutions at Elevated Temperatures and $\mathrm{CO}_{2}$ Pressures. Geochem. Int. 12, 199-201. 
125. Malinin S. D. and Savelyeva N. I. (1972) The Solubility of $\mathrm{CO}_{2}$ in $\mathrm{NaCl}$ and $\mathrm{CaCl}_{2}$ Solutions at 25,50 and $75^{\circ} \mathrm{C}$ under Elevated $\mathrm{CO}_{2}$ Pressures. Geochem. Int. 9, 410-418.

126. Mao S., Duan Z., Hu J. and Zhang D. (2010) A model for single-phase PVTx properties of $\mathrm{CO}_{2}-\mathrm{CH}_{4}-\mathrm{C}_{2} \mathrm{H}_{6}-\mathrm{N}_{2}-\mathrm{H}_{2} \mathrm{O}-\mathrm{NaCl}$ fluid mixtures from 273 to $1273 \mathrm{~K}$ and from 1 to 5000 bar. Chem. Geol. 275, 148-160.

127. Markowitz M. M. and Boryta D. A. (1961) A Thermodynamic Approach to the Measurement of Hygroscopicity. Aqueous Vapor Pressure of Univariant, Binary Systems, and Hygroscopicity Potential. J. Chem. Eng. Data 6, 16-18.

128. Marshall W. L., Loprest F. J. and Secoy C. H. (1958) The Equilibrium Li2CO3(s) + CO2 + $\mathrm{H} 2 \mathrm{O}[\mathrm{UNK}] 2 \mathrm{Li}++2 \mathrm{HCO} 3-$ at High Temperature and Pressure. J. Am. Chem. Soc. 80, 56465648 .

129. Martin A., Pham H. M., Kilzer A., Kareth S. and Weidner E. (2009) Phase equilibria of carbon dioxide + poly ethylene glycol + water mixtures at high pressure: Measurements and modelling. Fluid Phase Equilib. 286, 162-169.

130. Mashovets V. P., Zarembo V. I. and Fedorov M. K. (1973) Saturation vapor pressure of aqueous $\mathrm{NaCl}, \mathrm{NaBr}$, and $\mathrm{NaI}$ solutions at temperatures form 150 to $350 \mathrm{C}$. Zh. Prikl. Khim. 46, 650-652.

131. Mather A. E. and Franck E. U. (1992) Phase equilibria in the system carbon dioxide-water at elevated pressures. J. Phys. Chem. 96, 6-8.

132. McGee, K. A., Susak, N. J., Sutton, A. J., and Haas, J. L. (1981) The solubility of methane in sodium chloride brines. United States Department of the Interior Geological Survey Open-File Report 81-1294: 42.

133. Michels A., Gerver J. and Bijl A. (1936) The Influence of Pressure on the Solubility of Gases. Physica 3, 797-808.

134. Miljevic N., Dessauges G. and Hook W. A. (1981) Isotope effects in aqueous systems. X. Boiling point elevations for $\mathrm{NaCl}$ solutions in $\mathrm{H} 2 \mathrm{O}$ and D2O. J. Sol. Chem. 10, 29-38.

135. Mokbel I., Ye S., Jose J. and Xans P. (1997) Study of non ideality of various aqueous sodium chloride solutions by vapor pressure measurements and correlation of experimental results by Pitzer's method. J. Chim. Phys. PCB 94, 122-137.

136. Morales J. W., Galleguillos H. R., Taboada M. E. and Hernandez-Luis F. (2009) Activity coefficients of $\mathrm{NaCl}$ in PEG 4000 + water mixtures at 288.15, 298.15 and $308.15 \mathrm{~K}$. Fluid Phase Equilib. 281, 120-126.

137. Morgan O. M. and Maass O. (1931) An investigation of the equilibria existing in gas - water systems forming electrolytes. Can. J. Res. Sect. B 5, 162-199.

138. Mueller G., Bender E. and Maurer G. (1988) The vapor-liquid equilibrium of the ternary system ammonia - carbon dioxide - water at high water contents in the range $373-473 \mathrm{~K}$. Berich. Bunsen Gesell. 92, 148-160.

139. Nakayama T., Sagara H., Arai K. and Saito S. (1987) High pressure liquid-liquid equilibria for the system of water, ethanol and 1,1-difluoroethane at $323.2 \mathrm{~K}$. Fluid Phase Equilib. 38, 109-127. 
140. Nasirzadeh K., Zimin D., Neueder R. and Kunz W. (2004) Vapor-Pressure Measurements of Liquid Solutions at Different Temperatures: Apparatus for Use over an Extended Temperature Range and Some New Data. J. Chem. Eng. Data 49, 607-612.

141. Nighswander J. A., Kalogerakis N. and Mehrotra A. K. (1989) Solubilities of carbon dioxide in water and $1 \mathrm{wt}$ \% sodium chloride solution at pressures up to $10 \mathrm{MPa}$ and temperatures from 80 to 200.degree.C. J. Chem. Eng. Data 34, 355-360.

142. Novak J., Fried V. and Pick J. (1961) The Solubility of Carbon Dioxide in Water at various Pressures and Temperatures. Collect. Czech. Chem. Commun. 26, 2266-2270.

143. O'Sullivan T. D. (1970) The solubility and partial molar volume of Nitrogen and methane in water and in aqueous sodium chloride from 50 to $125 \varnothing \mathrm{C}$ and 100 to $600 \mathrm{Atm}$. J. Phys. Chem. $74,1460-1466$.

144. Olds R. H., Sage B. H. and Lacey W. N. (1942) Phase Equilibria in Hydrocarbon Systems.Composition of the Dew-Point Gas of the Methane-Water System. Ind. Eng. Chem. 34, 1223-1227.

145. Parisod C. J. and Plattner E. (1981) Vapor-liquid equilibriums of the sodium chloride-water system in the temperature range 300-440 .degree.C. J. Chem. Eng. Data 26, 16-20.

146. Partanen J. I. and Minkkinen P. O. (1993) Thermodynamic activity quantities in aqueous sodium and potassium chloride solutions at $298.15 \mathrm{~K}$ up to a molality of $2.0 \mathrm{~mol} / \mathrm{kg}$. Acta Chem. Scand. 47, 768-776.

147. Patel M. R., Holste J. C., Hall K. R. and Eubank P. T. (1987) Thermophysical properties of gaseous carbon dioxide + water mixtures. Fluid Phase Equilib. 36, 279-299.

148. Patel S. G. and Kishore N. (1995) Thermodynamics of nucleic acid bases and nucleosides in water from 25 to $55^{\circ} \mathrm{C}$. J. Sol. Chem. 24, 25-38.

149. Pearce J. N. and Nelson A. F. (1932) The vapor pressures of aqueous solutions of lithium nitrate and the activity coefficients of some alkali salts in solutions of high concentration at $25^{\circ} \mathrm{C}$. J. Am. Chem. Soc. 54, 3544-3555.

150. Pitzer K. S. (1973) Thermodynamics of Electrolytes I: Theoretical basis and general equations. J. Phys. Chem. 77, 268-277.

151. Platford R. F. (1968) Isopiestic measurements on the system water-sodium chloride-sulfuric acid disodium salt at 25.degree. J. Chem. Eng. Data 13, 46-48.

152. Pohorecki R. and Mozenski C. (1995) Studies of carbon dioxide solubility in propylene carbonate with the addition of triethanolamine. Inz. Chem. Procesowa 16, 117-132.

153. Potter R. W. and Brown D. L. (1977) The Volumetric Properties of Aqueous Sodium Chloride Solutions from $0 \mathrm{C}$ to $500 \mathrm{C}$ at Pressures up to 2000 Bars Based on a Regression of Available Data in the Literature. U. S. Geol. Surv. Bull. 1421.

154. Prutton C. F. (1945) The solubility of carbon dioxide in calcium chloride-water solutions at $75,100,120^{\circ} \mathrm{C}$ and high pressures. Journal of American Chemical Society $67,1550-1554$.

155. Qin J. F., Rosenbauer R. J. and Duan Z. (2008) Experimental measurements of vapor-liquid equilibria of the $\mathrm{H} 2 \mathrm{O}+\mathrm{CO} 2+\mathrm{CH} 4$ ternary system. J. Chem. Eng. Data 53, 1246-1249. 
156. Rabie H., Wilczek-Vera G. and Vera J. (1999) Activities of Individual Ions From Infinite Dilution to Saturated Solutions. J. Sol. Chem. 28, 885-913.

157. Rard J. A. and Archer D. G. (1995) Isopiestic Investigation of the Osmotic and Activity Coefficients of Aqueous $\mathrm{NaBr}$ and the Solubility of $\mathrm{NaBr} . c n t d o t .2 \mathrm{H} 2 \mathrm{O}(\mathrm{cr})$ at $298.15 \mathrm{~K}$ : Thermodynamic Properties of the $\mathrm{NaBr}+\mathrm{H} 2 \mathrm{O}$ System over Wide Ranges of Temperature and Pressure. J. Chem. Eng. Data 40, 170-185.

158. Rigby M. and Prausnitz J. M. (1968) Solubility of water in compressed nitrogen, argon, and methane. J. Phys. Chem. 72, 330-334.

159. Robinson R. A. and Stokes R. H. (1949) Tables of osmotic and activity coefficients of electrolytes in aqueous solution at 25[degree] C. T. Faraday Soc. 45, 612-624.

160. Robinson R. A. and Sinclair D. A. (1934) The Activity Coefficients of the Alkali Chlorides and of Lithium Iodide in Aqueous Solution from Vapor Pressure Measurements. J. Am. Chem. Soc. 56, 1830-1835.

161. Rodnyanskii I. M. and Galinker I. S. (1955) Electrical conductivity of aqueous $\mathrm{LiCl}, \mathrm{NaCl}$ and $\mathrm{KCl}$ solutions at high temperatures. Dokl. Akad. Nauk SSSR 105, 115-118.

162. Rogers P. S. Z. and Pitzer K. S. (1982) Volumetric Properties of Aqueous Sodium Chloride Solutions. J. Phys. Chem. Ref. Data 11, 15-81.

163. Rowley, J. R., Wilding, W., V, Oscarson, J. L., Yang, Y., and Giles, N. F. (2011) DIPPR (R) Data Compilation of Pure Chemical Properties. Design Institute for Physical Properties Data (DIPPR-AIChE).

164. Ruffine L. and Trusler J. P. M. (2010) Phase behaviour of mixed-gas hydrate systems containing carbon dioxide. J. Chem. Thermodyn. 42, 605-611.

165. Rumpf B., Nicolaisen H., Ocal C. and Maurer G. (1994) Solubility of carbon dioxide in aqueous solutions of sodium chloride: Experimental results and correlation. J. Sol. Chem. 23, 431-448.

166. Safona L. P., Egorova I. V. and Krestov G. A. (1986) Activity coefficients of sodium chloride in aqueous glycol solutions at various temperatures. Zh. Fiz. Khim. 60, 1770-1773.

167. Sako T., Sugeta T., Nakazawa N., Okubo T., Sato M., Taguchi T. and Hiaki T. (1991) Phase Equilibrium Study of Extraction and Concentration of Furfural Produced in Reactor Using Supercritical Carbon Dioxide. J. Chem. Eng. Jpn. 24, 449-455.

168. Salabat A., Shamshiri L. and Sahrakar F. (2005) Thermodynamic and transport properties of aqueous trisodium citrate system at 298.15 K. J. Mol. Liq. 118, 67-70.

169. Sanchez M. and de Meer F. (1978) Vapor-Liquid Equilibrium of the System Methane - Water at High Pressures and Temperatures between 150 and $300^{\circ} \mathrm{C}$. An. Quim. 74, 1325-1328.

170. Scatchard G., Hamer W. J. and Wood S. E. (1938) Isotonic Solutions. I. The Chemical Potential of Water in Aqueous Solutions of Sodium Chloride, Potassium Chloride, Sulfuric Acid, Sucrose, Urea and Glycerol at 25 . J. Am. Chem. Soc. 60, 3061-3070.

171. Schindler P. and Waelti E. (1968) Zur Bestimmung von Aktivitaten und Konzentrationen mit natriumempfindlichen Glaselektroden. HCA 51, 539-542.

172. Schmidt E. and Grigull U. (1982) Properties of water and steam in SI-units, Springer Verlag. 
173. Schneider A. C., Pasel C., Luckas M., Schmidt K. G. and Herbell J. D. (2003) Bestimmung von Ionenaktivitatskoeffizienten in wassrigen Losungen mit Hilfe ionenselektiver Elektroden. Chem. Ing. Tech. 75, 244-249.

174. Servio P. and Englezos P. (2001) Effect of temperature and pressure on the solubility of carbon dioxide in water in the presence of gas hydrate. Fluid Phase Equilib. 190, 127-134.

175. Sharma S. C. (1969) Equilibrium Water Content of Gaseous Mixtures. Ph. D. thesis, The University of Oklahoma.

176. Shreiber L. S. and Tikhii S. P. (1973) Influence of alkaline metal chloride additives and of the temperature on the structure of normal and heavy water. Zh. Fiz. Khim. 47, 698-700.

177. Silkenbaumer D., Rumpf B. and Lichtenthaler R. N. (1998) Solubility of carbon dioxide in aqueous solutions of 2-amino-2-methyl-1-propanol and $\mathrm{N}$-methyldiethanolamine and their mixtures in the temperature range from 313 to $353 \mathrm{~K}$ and pressures up to $2.7 \mathrm{MPa}$. Ind. Eng. Chem. Res. 37, 3133-3141.

178. Simonin J. P. (1997) Real ionic solutions in the mean spherical approximation .2. Pure strong electrolytes up to very high concentrations, and mixtures, in the primitive model. J. Phys. Chem. B 101, 4313-4320.

179. Siqueira Campos C. E. P., Penello J. R., Pellegrini Pessoa F. L. and Cohen Uller A. M. (2010) Experimental Measurement and Thermodynamic Modeling for the Solubility of Methane in Water and Hexadecane. J. Chem. Eng. Data 55, 2576-2580.

180. Smith H. A., Combs R. L. and Googin J. M. (1954) Vapor Pressure Studies Involving Solutions in Light and Heavy Waters. I. The Apparatus and the Determination of Vapor Pressures at $30^{\circ}$ of Solutions of Sodium and Potassium Chlorides in Ordinary Water. J. Phys. Chem. 58, 997-999.

181. Smith R. P. (1939) The Boiling Point Elevation. II. Sodium Chloride 0.05 to $1.0 \mathrm{M}$ and 60 to $100^{\circ}$.J. Am. Chem. Soc. 61, 500-503.

182. Soave G. (1972) Equilibrium constants from a modified Redlich-Kwong equation of state. Chem. Eng. Sci. 27, 1197-1203.

183. Soreide I. and Whitson C. (1992) Peng-Robinson predictions for hydrocarbons, $\mathrm{CO}_{2}, \mathrm{~N}_{2}$, and $\mathrm{H}_{2} \mathrm{~S}$ with pure water and $\mathrm{NaCl}$ brine. Fluid Phase Equilib. 77, 217-240.

184. Sorensen H., Pedersen K. S. and Christensen P. L. (2002) Modeling of gas solubility in brines. Org. Geochem. 33, 635-642.

185. Sourirajan S. and Kennedy G. C. (1962) The system $\mathrm{H} 2 \mathrm{O}-\mathrm{NaCl}$ at elevated temperatures and pressures. Am. J. Sci. 260, 115-141.

186. Stewart P. B. and Munjal P. K. (1970) Solubility of carbon dioxide in pure water, synthetic sea water, and synthetic sea water concentrates at -5 .deg. to $25 . \mathrm{deg}$. and 10- to 45 -atm. pressure. J. Chem. Eng. Data 15, 67-71.

187. Stokes R. H. and Levien B. J. (1946) The Osmotic and Activity Coefficients of Zinc Nitrate, Zinc Perchlorate and Magnesium Perchlorate. Transference Numbers in Zinc Perchlorate Solutions. J. Am. Chem. Soc. 68, 333-337.

188. Sultanov R. G. (1972) Phase equilibrium of methane and nitrogen in a mixture with a hydrocarbon of low volatility. Gazovoe Delo 10, 43-46. 
189. Sultanov R. G., Skripka V. G. and Namiot A. Y. (1971) Moisture Content of Methane at high Temperatures and Pressures. Gazov. Promst. 16, 6-8.

190. Tabasinejad F., Moore R. G., Mehta S. A., Van Fraassen K. C., Barzin Y., Rushing J. A. and Newsham K. E. (2011) Water Solubility in Supercritical Methane, Nitrogen, and Carbon Dioxide: Measurement and Modeling from 422 to $483 \mathrm{~K}$ and Pressures from 3.6 to $134 \mathrm{MPa}$. Ind. Eng. Chem. Res. 50, 4029-4041.

191. Takenouchi S. and Kennedy G. G. (1964) The binary system $\mathrm{H}_{2} \mathrm{O}-\mathrm{CO}_{2}$ at high temperatures and pressures. Am. J. Sci. 262, 1055-1074.

192. Takenouchi S. and Kennedy G. G. (1965) The solubility of carbon dioxide in $\mathrm{NaCl}$ solutions at high temperatures and pressures. Am. J. Sci. 263, 445-454.

193. Tammann G. (1888) The vapor tensions of solutions. Z. Phys. Chem. Leipzig 2, 42-47.

194. Todheide K. and Franck E. U. (1963) Das Zweiphasengebiet und die kritische Kurve im system Kohlendioxid-wasser bis zu drucken von 3500 bar. Zeit. Phys. Chem. Neue Fol. 37, $387-401$.

195. Tsivintzelis I., Kontogeorgis G. M., Michelsen M. L. and Stenby E. H. (2010) Modeling phase equilibria for acid gas mixtures using the CPA equation of state. I. Mixtures with H2S. AIChE J. 56, 2965-2982.

196. Tsivintzelis I., Kontogeorgis G. M., Michelsen M. L. and Stenby E. H. (2011) Modeling phase equilibria for acid gas mixtures using the CPA equation of state. Part II: Binary mixtures with CO2. Fluid Phase Equilib. 306, 38-56.

197. Ugrozov V. V. (1996) Equilibrium compositions of vapor-gas mixtures over solutions. $Z$ h. Fiz. Khim. 70, 1328-1329.

198. Urusova M. A. and Ravich M. I. (1971) Vapour Pressure and Solubility in the Sodium Chloride - Water System at 350 and $400^{\circ} \mathrm{C}$. Russ. J. Inorg. Chem. 16, 1534-1535.

199. Valtz A., Chapoy A., Coquelet C., Paricaud P. and Richon D. (2004) Vapour-liquid equilibria in the carbon dioxide-water system, measurement and modelling from 278.2 to $318.2 \mathrm{~K}$. Fluid Phase Equilib. 226, 333-344.

200. Verbrugge P. (1979) Vapor-Liquid Equilibria of the Ammonia - Carbon Dioxide - Water System. Ph. D. thesis, TH, Delft, NL.

201. Vilcu R. and Gainar I. (1967) Solubility of gases in liquids under pressure. I. The system carbon dioxide - water. Rev. Roum. Chim. 12, 189.

202. Vlasov Y. G. (1963) Aqueous vapor pressure over sodium chloride solutions and activity coefficients of sodium chloride at $45^{\circ} \mathrm{C}$. Russ. J. Phys. Chem. 37, 1399-1400.

203. Wang J., Liu W., Fan J. and Lu J. (1994) Mean activity coefficients of $\mathrm{NaCl}$ in glucose-water and sucrose-water mixtures at 298.15 K. J. Chem. Soc. , Faraday Trans. 90, 3281-3285.

204. Wang Y., Han B., Yan H. and Liu R. (1995) Solubility of CH4 in the mixed solvent t-butyl alcohol and water. Thermochim. Acta 253, 327-334.

205. Welsch H. (1973) The systems xenon - water and methane - water at high pressures and temperatures. Ph. D. thesis, Universitaet Karlsruhe. 
206. Wertheim M. S. (1984) Fluids with Highly directional attractive forces. I. Statistical thermodynamics. J. Stat. Phys. 35, 19-34.

207. Wiebe R. (1939) The solubility in water of carbon dioxide at 50,75 and $100 \varnothing \mathrm{C}$, at pressure to 700 atmospheres. Journal of American Chemical Society 61, 315-318.

208. Wiebe R. and Gaddy V. L. (1940) The Solubility of Carbon Dioxide in Water at Various Temperatures from 12 to $40^{\circ} \mathrm{C}$ and at Pressures to 500 Atmospheres. Critical Phenomena. $J$. Am. Chem. Soc. 62, 815-817.

209. Wigent R. J. and Leifer L. (1984) Determination of osmotic and activity coefficients in mixed electrolyte systems. Systems containing clathrate-forming salts. J. Phys. Chem. 88, 44204426.

210. Wilczek-Vera G., Rodil E. and Vera J. H. (2006) Towards accurate values of individual ion activities: Additional data for $\mathrm{NaCl}, \mathrm{NaBr}$ and $\mathrm{KCl}$, and new data for $\mathrm{NH} 4 \mathrm{Cl}$. Fluid Phase Equilib. 241, 59-69.

211. Wu Y. C., Rush R. M. and Scatchard G. (1969) Osmotic and activity coefficients for binary mixtures of sodium chloride, sodium sulfate, magnesium sulfate, and magnesium chloride in water at 25.deg.. II. Isopiestic and electromotive force measurements on the two systems without common ions. J. Phys. Chem. 73, 2047-2053.

212. Yan W. D., Xu Y. J. and Han S. J. (1994) Activity Coefficients of Sodium Chloride in Methanol - Water Mixed Solvents at 298.15 K. Hua Hsueh Hsueh Pao 52, 937-946.

213. Yang S. O., Cho S. H., Lee H. and Lee C. S. (2001) Measurement and prediction of phase equilibria for water + methane in hydrate forming conditions. Fluid Phase Equilib. 185, 53 63.

214. Yao J., Yan W. d., Xu Y.j. and Han S. j. (1999) Activity Coefficients for $\mathrm{NaCl}$ in $\mathrm{MeOH}+$ $\mathrm{H} 2 \mathrm{O}$ by Electromotive Force Measurements at $308.15 \mathrm{~K}$ and $318.15 \mathrm{~K}$. J. Chem. Eng. Data 44, 497-500.

215. Yarim-Agaev N. L., Sinyavskaya R. P., Koliushko I. I. and Levington L. Y. (1985) Phase Equilibria in the Water - Methane and Methanol - Methane Binary Systems under High Pressures. J. Appl. Chem. USSR 58, 154-157.

216. Yarrison M., Cox K. R. and Chapman W. G. (2006) Measurement and Modeling of the Solubility of Water in Supercritical Methane and Ethane from 310 to $477 \mathrm{~K}$ and Pressures from 3.4 to $110 \mathrm{MPa}$. Ind. Eng. Chem. Res. 45, 6770-6777.

217. Yin S., Yao Y., Li B., Tian H. B. and Song P. (2007) Isopiestic Studies of Aqueous MgB4O7 and MgSO4 + MgB4O7 at 298.15 K and Representation with Pitzer's Ion-Interaction Model. J. Sol. Chem. 36, 1745-1761.

218. Yokoyama C., Wakana S., Kaminishi G. and Takahashi S. (1988) Vapor-liquid equilibria in the methane-diethylene glycol-water system at 298.15 and 323.15 K. J. Chem. Eng. Data 33, 274-276.

219. Zaalishvili S. D. (1940) The solubility of carbon dioxide mixed with hydrogen and nitrogen in water under pressure. Zh. Fiz. Khim. 14, 413-417.

220. Zarembo V. I. and Fedorov M. K. (1975) Density of sodium chloride solutions in the temperature range $25-350 \mathrm{C}$ at pressures up to $1000 \mathrm{~kg} / \mathrm{cm} 2 . J$. Appl. Chem. 48, 2021-2024. 
221. Zawisza A. and Malesinska B. (1981) Solubility of carbon dioxide in liquid water and of water in gaseous carbon dioxide in the range $0.2-5 \mathrm{MPa}$ and at temperatures up to $473 \mathrm{~K}$. J. Chem. Eng. Data 26, 388-391.

222. Zel'vinskii Ya. D. (1937) Solubility of $\mathrm{CO}_{2}$ in Water under Pressure. Zh. Khim. Prom. 14, 1250-1257.

223. Zheng D. Q., Guo T. M. and Knapp H. (1997) Experimental and modeling studies on the solubility of $\mathrm{CO} 2, \mathrm{CHC} 1 \mathrm{~F} 2, \mathrm{CHF} 3, \mathrm{C} 2 \mathrm{H} 2 \mathrm{~F} 4$ and $\mathrm{C} 2 \mathrm{H} 4 \mathrm{~F} 2$ in water and aqueous $\mathrm{NaCl}$ solutions under low pressures. Fluid Phase Equilib. 129, 197-209.

224. Zhuo K., Dong W., Wang W. and Wang J. (2008) Activity coefficients of individual ions in aqueous solutions of sodium halides at 298.15 K. Fluid Phase Equilib. 274, 80-84. 
